\title{
Arqueologia Entre Rios: do Urussanga ao Mampituba. Paleoambiente, cultura material e ocupação humana na paisagem litorânea do extremo Sul catarinense entre 3.500-200 anos AP
}

\author{
Marcos César Pereira Santos*, Diego Dias Pavei** e Juliano Bitencourt Campos***
}

Palavras-chave: Arqueologia

Costeira; Sistema Lagunar; Sul de Santa Catarina.

Keywords: Coast Archaeology; Lagoon System; South of Santa Catarina State.
Resumo: Este artigo apresenta uma proposta de sequência arqueológica regional para a Planície Costeira do Extremo Sul Catarinense, com cronologia média entre os 3.500-235 anos AP. Os dados baseiam-se nos resultados dos estudos realizados no projeto de pesquisa Arqueologia Entre Rios: do Urussanga ao Mampituba (AERUM). O setor Norte do projeto AERUM é apresentado no presente artigo como modelo de integração dos dados. Em $286 \mathrm{~km}^{2}$, foram encontrados 53 sítios arqueológicos relacionados a duas fases paleoambientais associadas ao estabelecimento da floresta tropical úmida na região. Existem quatro conjuntos arqueológicos diferenciados: sítios líticos com pontas bifaciais relacionadas à tradição Umbu; sítios concheiros de diferentes cronologias e associados a Sambaquis Plenos (fase 3), Tardios e/ou Jê Meridionais (fase 4) e Guarani (fase 4); e sítios ceramistas com formação de Terra Preta Arqueológica (TPA) associados a grupos Guarani. Os resultados nos permitiram inferir, em uma perspectiva regional, quais grupos pré-históricos ocuparam a região no tempo e no espaço, assim como suas adaptações culturais às paleopaisagens.

Abstract: This paper presents an archaeological sequence propose for the region of the coastal plain of the Extreme South of Santa Catarina state. The chronology dates between 3.697 and 230 year BP. These data are based on the results of studies developed within the research project "Archaeology Between Rivers: from Urussanga to Mampituba". The North sector of the AERUM project is presented in this article as the data integration model. In $286 \mathrm{~km}^{2}$, were found 53 archaeological sites related to two paleoenvironmental phases associated with the establishment of the humid tropical forest in the region. There are four different archaeological groups: lithic sites with bifacial points related to Umbu Tradition; shellmiddens sites of different chronologies and associated with Sambaqui Plenos (fase 3), Sambaqui Tardio and/or Jê of Southern Brazil (fase 4) and Guarani (fase 4); and ceramic sites with anthropological soil formation related to Guarani groups. The results allowed us to infer, in regional perspective, which prehistoric groups occupied the region in time and space, as well, their cultural adaptations to paleolandscapes.

Recebido em 11 de abril de 2016. Aprovado em 06 de junho de 2016.

\section{Introdução}

As ocupações pré-históricas na vertente Atlântica do Sul de Santa Catarina têm como palco paisagístico as feições geomorfológicas marcadas pelo abrupto desnível entre o Planalto e os vales escarpados da Serra Geral, os alinhamentos serranos e morros isolados (espigões) - que se projetam em direção ao litoral - e a extensa planície costeira. Os dados arqueológicos pré-históricos advindos dessa região apresentam cerca de 6.000 anos de ocupações ininterruptas, mas sem clara linearidade diacrônica entre os sítios arqueológicos das encostas da Serra Geral e os encontrados na Planície Litorânea por grupos associados arqueologicamente às tradições Umbu, Sambaquieiras, Jê Meridionais e

\footnotetext{
*Laboratório de Arqueologia Pedro Ignácio Schmitz (LAPIS); Grupo de Pesquisa em Arqueologia e Gestão Integrada do Território; Universidade do Extremo Sul Catarinense (UNESC). Università degli Studi di Ferrara - International Doctorate in Quaternary and Prehistory (IDQP). E-mail: marcoscesar@unesc.net.

** Laboratório de Arqueologia Pedro Ignácio Schmitz (LAPIS); Grupo de Pesquisa em Arqueologia e Gestão Integrada do Território; Universidade do Extremo Sul Catarinense (UNESC). E-mail: diego.pavei@unesc.net.

*** Laboratório de Arqueologia Pedro Ignácio Schmitz (LAPIS); Grupo de Pesquisa em Arqueologia e Gestão Integrada do Território; Programa de Pós-Graduação em Ciências Ambientais (PPGCA)Universidade do Extremo Sul Catarinense (UNESC). E-mail: jbi@unesc.net.
} 
Guarani. Entretanto, é no litoral que se observa mais claramente essa constante e diferenciada ocupação ao longo dos milênios, a qual resultou em agrupamentos regionais de sítios conchíferos com longas sequências estratigráficas, na formação de solos antropogênicos associados a grupos ceramistas e esporádicos sítios líticos a céu aberto com e sem pontas bifaciais típicas da tradição Umbu. Estes últimos sítios apresentam larga distribuição quantitativa, principalmente na região das Encostas e dos morros isolados interioranos (CAMPOS et al., 2013; CAMPOS, 2015; DEBLASIS et al., 2007; DEBLASIS; GASPAR, 2009; FARIAS et al., 2013; FARIAS; SCHIMTZ, 2012; 2013; MILHEIRA; DEBLASIS, 2013).

Nesse contexto regional, o Extremo Sul Catarinense foi alvo de pesquisas arqueológicas esporádicas no início dos anos 1980 (LINO; CAMPOS, 2003; FARIAS, 2005; ROHR, 1982; SCHMITZ, 1995-1996, 1998; SCHMITZ et al., 1999). No entanto, até 2011, a maior parte dos dados arqueológicos da região resultaram, direta ou indiretamente, do trabalho de licenciamento ambiental (CALDARELLI, 2003; CAMPOS, 2008, 2009, 2010, 2011; CAMPOS; SANTOS, 2014; FOSSARI, 1991; LAVINA, 1997-1998, 2000, 2003, 2005; LINO, 2009). Tais trabalhos não tinham a perspectiva da arqueologia regional, mas forneceram dados quantitativos ligados, principalmente, ao mapeamento e à caracterização tipológica da distribuição dos sítios arqueológicos nas diferentes unidades geomorfológicas.

A partir de 2012, teve início um projeto de pesquisa regional e permanente, com foco na temática pré-histórica. Os objetivos foram: 1) sistematização dos dados das pesquisas anteriores; 2) novas prospecções; 3) novas escavações; 4) estudo de materiais arqueológicos; 5) pesquisas interdisciplinares com enfoque paleoambiental; 6) realização de novas datações para definir a cronologia litorânea (CAMPOS et al., 2012; CAMPOS et al., 2013; CAMPOS, 2015; CEZARO et al., 2011, 2013; PEREIRA et al., 2016; RICKEN et al., 2013; SANTOS et al., 2014; SANTOS et al., 2015; VAL, 2015).

$\mathrm{O}$ conjunto dos dados indica que a área do projeto AERUM foi ocupada, inicialmente, por grupos com hábitos de caça, pesca e coleta e, posteriormente, por ceramistas e agricultores de policultura agroflorestal, além de diferenciados sítios de Arte Rupestre (arte móvel, matacões em contexto fluvial e paleotocas), dentro de um panorama conhecido no contexto da Arqueologia Meridional Brasileira, dividido em: Caçadores-Coletores (Tradição Umbu), Pescadores-Coletores (Sambaquis) e Agricultores (Jê Meridional e Guarani) (BONOMO et al., 2015; CORTELETTI, 2012; DEBLASIS et al., 2007; DIAS, 2007, 2012; FARIAS; SCHMITZ, 2012; MILHEIRA; DEBLASIS, 2013; NOELLI, 1999-2000; SCHMITZ et al., 2009; SCHMITZ, 2013).

O setor Norte do projeto AERUM (Figura 1) é apresentado neste artigo como modelo de integração dos dados, pois é a área focada nos primeiros anos da pesquisa, onde se encontra a maior parte dos sítios arqueológicos registrados na Planície Costeira do extremo sul de Santa Catarina. Ali existem sítios líticos com pontas bifaciais relacionadas à tradição Umbu; sítios concheiros de diferentes cronologias, associados aos Sambaquis Plenos (fase 3) e Tardios (fase 4) e aos Jê Meridionais e Guarani (fase 4); e sítios com Terra Preta Arqueológica (TPA) dos grupos Guarani (CAMPOS et al., 2013; CAMPOS, 2015).

O levantamento dos sítios arqueológicos préhistóricos da área foi executado a partir da revisão de fontes bibliográficas e consulta no CNSA/IPHAN. Também seguiu em campo a metodologia dos geoindicadores (MORAIS, 1999) e entrevistas com as comunidades. Foi realizado o registro de todos os sítios, retornando aos conhecidos e localizando novos, conforme a ficha de registro de sítios arqueológicos do IPHAN. Apoiados na bibliografia regional, optamos, inicialmente, por definir a divisão dos sítios arqueológicos por tipologias, segundo a cultura material e os padrões de inserção que os definem: concheiros (Sambaquis), litocerâmicos (Guarani) e sítios predominantemente líticos (com presença/ausência de pontas bifaciais típicas da tradição Umbu).

\section{Localização da Área de Estudo}

A área de estudo está localizada entre o Balneário Paiquerê e a foz do rio Urussanga, no sentido sul-norte, e entre o Oceano Atlântico e o 
traçado da BR 101, no sentido leste-oeste. Abrange uma área de $286 \mathrm{~km}^{2}(26 \mathrm{x} 11 \mathrm{~km})$, entre as coordenadas UTM: 655021 E e 6798994 N e 677434 E e 6813036 N (Figura 1). Está nos setores VIII e VII do compartimento meridional da Planície Costeira do sul do estado de Santa Catarina (HORN FILHO, 2003) e situa-se entre o primeiro terraço delimitado pela Barreira Arenosa Pleistocênica III (Barreira III) e a atual planície de inundação do rio dos Porcos e a linha da costa oceânica.

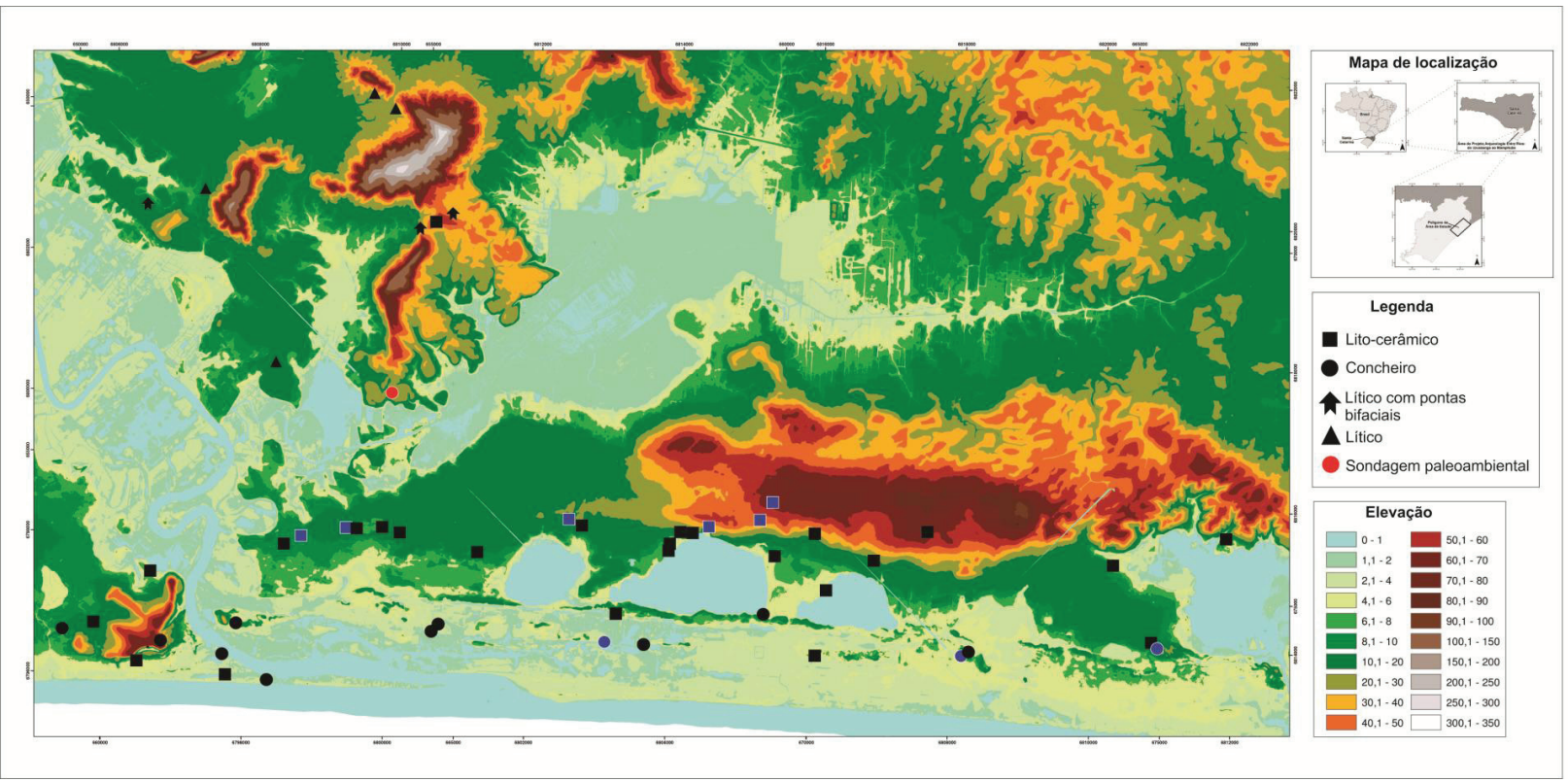

Figura 1 - Localização da área Norte do AERUM estudada. Aproximadamente $286 \mathrm{~km}^{2}(26$ x $11 \mathrm{~km})$ entre as coordenadas UTM 22J: 655021 E e 6798994 N e 677434 E e 6813036 N. Os sítios escavados na área estão evidenciados em azul. $O$ ponto vermelho indica onde foi realizada a sondagem para a reconstrução paleoambiental. Fonte: Elaborada pelos autores.

\section{Meio Físico}

A geologia é marcada pela presença das unidades de rochas ígneas e sedimentares pertencentes ao Cretáceo da sequência gondwânica da borda leste da Bacia Sedimentar do Paraná e dos extensos depósitos de leques aluviais (JUSTUS et al., 1986; KAUL, 1990).

Os sedimentos quaternários são abundantes nos cursos d'água, ocorrendo também depósitos arenosos de origem transicional (praial) e do retrabalhamento eólico (DUARTE, 1995; JUSTUS et al., 1986; KAUL, 1990; KREBS, 2004; MAACK, 1947; PAUWELLS, 1941). A porção Leste da área está no domínio geomorfológico da Planície Litorânea; já a porção Oeste fica nos domínios geomorfológicos da Zona Carbonífera Catarinense (morros testemunhos) e das Planícies Colúvio-Aluvionares (SANTA CATARINA, 1986; EPAGRI/CIRAM, 2011). A área é drenada, em sua maior parte, pelos tributários do rio
Araranguá e, em uma pequena parte, em sua porção extremo norte-nordeste, pelo rio Urussanga (SANTA CATARINA, 1997; SCHEIBE, 2010). Ocorrem nesta porção, de acordo com a EPAGRI e o CIRAM (2011), os seguintes solos: Argissolos, Cambissolos, Espodossolos, Gleissolos, Organossolos, Neossolos Quartzarênicos, Nitossolos e as Dunas.

A cobertura vegetal do litoral para o interior do continente está representada pelas seguintes formações: Vegetação Pioneira sob Influência Marinha - Restingas, a Floresta Ombrófila Densa das Terras Baixas e a Floresta Ombrófila Densa Submontana (TEIXEIRA et al., 1986; LEITE; KLEIN, 1990; IBGE, 1992).

\section{Dados Paleoambientais}

$\mathrm{Na}$ área de abrangência do AERUM, entre os cordões de dunas holocênicas, deságuam, em forma de estuário, os rios pertencentes às bacias 
do Urussanga, do Araranguá, do Mampituba e 11 lagoas. Os estuários das bacias do Urussanga e do Araranguá são assoreados constantemente por cordões arenosos oriundos do processo de ondas de alta energia, redirecionando a desembocadura desses rios na direção Norte.

Dentro desse contexto litorâneo dinâmico, são utilizadas duas pesquisas paleopalinológicas como referências para as interpretações paleoambientais do AERUM: Cancelli (2012), no limite Sul, e Val (2015), no limite Norte. Para este artigo, foram analisados apenas os registros palinilógicos da parte Norte, integrando-os aos dados sedimentares e altimétricos para reconstruir as características gerais da evolução paleoambiental em três fases distintas durante os últimos 8.000 anos AP. Essas informações indicam que a área evoluiu a partir de um ambiente estuarino/lagunar (Fase I: 7.995 \pm 35 cal AP-6.810 AP, idade interpolada) com vegetação predominantemente herbácea, passando pela consolidação de uma lagoa que, progressivamente, se converteu em um pântano costeiro (Fase II. a: 6.810 AP interpolada-cal. 4.000 AP; Fase II. b: cal. 4.000-2.797/2.205 cal AP), com vegetação herbácea e alguns táxons arbóreos, até o seu desaparecimento favorecido pela diminuição da influência marinha e expansão da Floresta Ombrófila Densa (Fase III: 2.797/2.205 cal AP-presente) (VAL, 2015).

A composição da arqueofauna da área do Projeto AERUM está baseada, até o momento, nas análises zooarqueológicas dos sítios concheiros Sambaqui do Geraldo, Sambaqui Içara 01 e Sambaqui Lagoa dos Freitas, conforme Campos (2015). Os dois primeiros foram escavados pela equipe do IAPUNISINOS (ROSA, 1998, 1999, 2006; TAMIOZZO; ROSA; SCHMITZ, 2008; TEIXEIRA, 2006), e o último está associado às novas escavações do projeto AERUM, realizadas a partir de 2014.

Os dados indicam que o sítio arqueológico Sambaqui do Geraldo, datado em 3.697-3.377 cal anos AP, foi um assentamento com tendência à exploração de recursos marinhos, enquanto o aproveitamento de recursos terrestres é menos representativo (ROGGE; ARNT, 2006). A abundância de restos de peixes e aves marinhas evidencia a relação dos ocupantes do sítio com o mar, representada pela significativa presença de quantidades de espécies, sobretudo a família Ariidae, que compreende os bagres marinhos anádromos, habitantes de lugares rasos em fundo lodoso, buscando estuários, baías e barras de rios para a reprodução. Foram registrados, também, restos esqueletais de Ragiformes (arraias), de Micropogonias furnieri (Desmarest, 1823) (corvina), de Pogonias cromis (Linnaeus, 1766) (miraguaias), de Archosargus sp. Gill, 1865 (sargo) e de Centropomus sp. Lacépède, 1802 (TEIXEIRA, 2006).

O sítio Sambaqui Içara 01, datado em 1.532-1.184cal anos AP, caracteriza-se como um cemitério com 84 enterramentos primários e secundários (SCHMITZ, 1999), onde as espécies contrastam com as encontradas no Sambaqui do Geraldo, principalmente nas porcentagens de ictiofauna e mastofauna terrestre. A classe Mammalia apresenta maior abundância na fauna terrestre, com representantes de animais de médio e grande porte, como o Mazama sp. Rafinesque, 1817 (veado), o Ozotoceros bezoarticus (Linnaeus, 1758) (veadogalheiro), Tapirus terrestris (Linnaeus, 1758) (anta), Tayassu pecari (Link, 1795) (queixada) e Hydrochoerus hydrochaeris (Linnaeus, 1766) (capivaras). Esses animais habitam os interiores das matas fechadas, exceto o O. Bezoarticus e o H. Hydrochaeris, que ocupam lugares de vegetação predominantemente herbácea e arbustos. A mastofauna do sítio também apresenta espécies de pequeno porte, desde marsupiais didelfídeos, roedores como Cuniculus paca (Linnaeus, 1766) (paca), Ctenomys sp. Blainville, 1826 (tuco-tuco) e Myocastor coypus (Molina, 1782) (ratão-do-banhado), e também os dasipodídeos, representados pelos tatus (ROSA, 2006).

O sítio Sambaqui Lagoa dos Freitas apresenta dois horizontes cronológicos: um mais antigo, entre 1360-1275 cal AP, e um mais recente, entre 495-230 cal AP. A arqueofauna identificada até o momento não indicou mudanças significativas entre os dois horizontes, sendo composta por peixes de hábitos estuarinos e lagunares e mamíferos terrestres de pequeno e médio porte. Os peixes estão relacionados às espécies Genidens sp. Castelnau, 1855 (Bagres), M. furnieri (corvina), e os mamíferos terrestres são representados, em maior abundância, pelo taxa Tayassuidae (porco-do-mato). No entanto, também 
aparecem espécies relacionadas aos taxa cf. Mazama sp. (veado), Didelphidae (Gray, 1821) (gambá), roedores, Ctenomys minutus Nehring, 1887 (tucotuco) e Sigmodontinae (pequenos roedores) (PAVEI; CAMPOS; SANTOS, 2016).

Os dados dos três concheiros indicam, até o momento, que existe uma diferença na exploração dos recursos faunísticos entre o horizonte mais antigo (3.697-3.377 anos AP) e o mais recente (1.532-1.184 anos AP). No horizonte mais antigo, houve maior abundância e diversidade de espécies ecologicamente associadas a hábitos costeiros, marítimos e dulcícolas (peixes de água doce). No horizonte mais recente, houve redução da diversidade de espécies marinhas; em contrapartida, vê-se a abundância dos peixes bagres e corvinas associada ao aumento da presença de mamíferos terrestres, principalmente dos taiaçuídeos (porco do mato) (Gráfico 1).

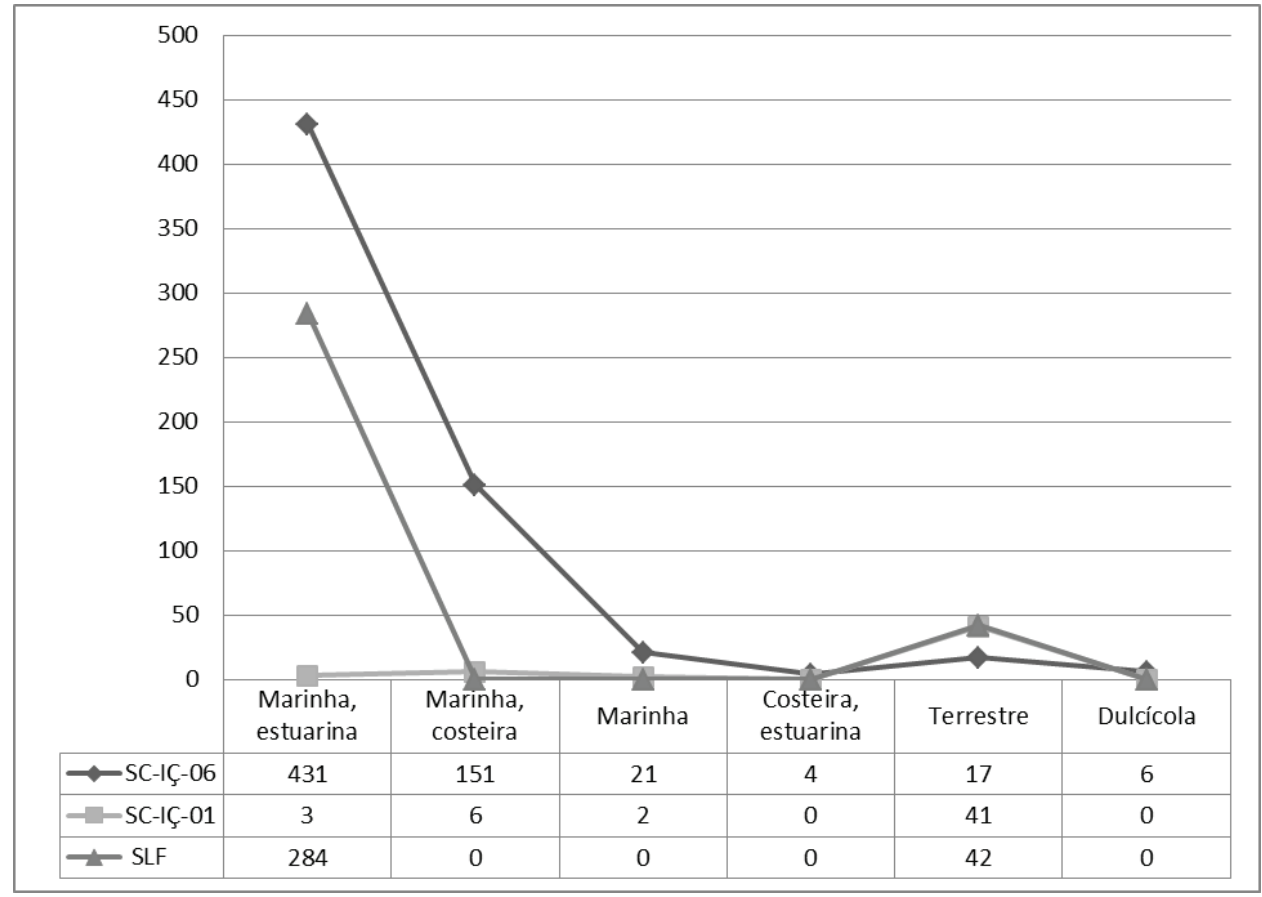

Gráfico 1 - Índices de abundância (NMI) da arqueofauna identificada até o momento nos sítios: Horizonte 1 Sambaqui do Geraldo (SC-IÇ-06). Horizonte 2 - Sambaqui Içara 01 (SC-IÇ-01) e Sambaqui Lagoa dos Freitas (SLF) Fonte: Elaborado pelos autores.

\section{Distribuição dos sítios arqueológicos}

A localização de sítios arqueológicos e sua relação com a dinâmica litorânea é etapa fundamental para a interpretação dos contextos arqueológicos (GIANNINI et al., 2010). Sendo assim, neste estudo, optou-se por cruzar a localização dos sítios com as características litológicas, pedológicas e potencial vegetacional, buscando um entendimento integrado entre os diferentes contextos geológicogeomorfológico, botânico e arqueológico.

Foram registrados 53 sítios arqueológicos (Tabela 1) classificados inicialmente como: Guarani $(\mathrm{n}=32)$, Sambaqui $(\mathrm{n}=12)$ e Líticos $(\mathrm{n}=9)$, todos a céu aberto. Das 11 formações litológicas descritas para a área de pesquisa, em seis formações foram registrados assentamentos arqueológicos pré-históricos. Nas formações Laguna-Barreira Pleistocênica ( $\mathrm{QPb})$ e Laguna-Barreira Holocênica $(\mathrm{QHb})$, destaca-se a ocorrência de aproximadamente $77 \%$ do total de sítios arqueológicos. Nas demais formações, o número de registros é pouco expressivo.

O cruzamento das tipologias dos sítios com as litologias presentes na área (Tabela 1) mostra que os sítios Sambaqui $(n=9)$ estão estabelecidos predominantemente sobre os Depósitos Praiais Marinhos e Eólicos da Laguna-Barreira Holocênica $(\mathrm{QHb})$; os sítios Guarani $(\mathrm{n}=21)$ estão estabelecidos 
predominantemente sobre os Depósitos Praiais Marinhos e Eólicos da Laguna-Barreira Pleistocênica $(\mathrm{QPb})$; os sítios Líticos estão estabelecidos preferencialmente sobre a Formação Estrada Nova (Pen) e sobre os Depósitos Praiais Marinhos e Eólicos da Laguna-Barreira Pleistocênica $(\mathrm{QPb})(\mathrm{n}=3)$.

Tabela 1 - Distribuição das diferentes tipologias de sítios arqueológicos nas formações litológicas presentes no AERUM, conforme Krebs (2004) em que: $\mathrm{QPb}=$ Depósitos Praiais Marinhos e Eólicos (Laguna-Barreira Pleistocênica); QHb = Depósitos Praiais Marinhos e Eólicos (Laguna-Barreira Holocênica); QHfl = Depósitos Fluviolagunares (Quaternário Holoceno); Pen = Formação Estrada Nova (Paleozoico-Mesozoico); Ksg = Formação Serra Geral (Grupo São Bento): e PTRrr = Formação Rio do Rastro (Grupo Passa Dois)

\begin{tabular}{|c|c|c|c|c|c|c|c|c|}
\hline \multirow{3}{*}{$\begin{array}{l}\text { Formação } \\
\text { Litológica }\end{array}$} & \multicolumn{6}{|c|}{ Sítios Arqueológicos } & \multirow{3}{*}{ Total } & \multirow{3}{*}{$(\%)$} \\
\hline & \multicolumn{2}{|c|}{ Guarani } & \multicolumn{2}{|c|}{ Sambaqui } & \multicolumn{2}{|c|}{ Litico } & & \\
\hline & Registros & $(\%)$ & Registros & $(\%)$ & Registros & $(\%)$ & & \\
\hline (QPb) & 21 & 65,6 & 1 & 8,3 & 3 & 33,3 & 25 & 47,2 \\
\hline (QHb) & 6 & 18,8 & 9 & 75,0 & 1 & 11,1 & 16 & 30,2 \\
\hline (QHfl) & 3 & 9,4 & 2 & 16,7 & 0 & 0 & 5 & 9,4 \\
\hline (Pen) & 0 & 0 & 0 & 0 & 4 & 44,4 & 4 & 7,5 \\
\hline (Ksg) & 1 & 3,1 & 0 & 0 & 1 & 11,1 & 2 & 3,8 \\
\hline (PTRrr) & 1 & 3,1 & 0 & 0 & 0 & 0 & 1 & 1,9 \\
\hline Total & 32 & 100 & 12 & 100 & 9 & 100 & 53 & 100 \\
\hline
\end{tabular}

Fonte: Elaborada pelos autores.

A distribuição dos sítios nos diferentes tipos de solos mapeados na área indicou que 46,3\% ( $\mathrm{n}=$ 25) dos sítios registrados estão localizados sobre os Neossolos Quartzarênicos, representados pelos tipos AQd (areias quartzosas) e Ama4 (areias quartzosas marinhas). $29 \%(\mathrm{n}=15)$ estão assentados sobre os Argilossolos (PEa7, PVd1e PVa22); 16,7\% ( $\mathrm{n}=9$ ) sobre as Dunas (D) e 7,4\% $(\mathrm{n}=4)$ sobre os Gleissolos dos sítios registrados (Tabela 2 ).

A distribuição das tipologias de sítios sobre os diferentes tipos de solo é apresentada na
Tabela 2. 56\% dos sítios Guarani estão associados preferencialmente aos Neossolos (AQd e Ama4) e às Dunas (D), mas também há uma alta associação (31\%) com os Argilossolos (PEa7 e PVd1). Os sítios Sambaqui, em sua maior parte $(60,6 \%)$, encontram-se assentados sobre os Neossolos (AQd e Ama4), mas também têm alta associação $(41,7 \%)$ com as Dunas. Os sítios líticos, por sua vez, estão distribuídos, em sua maior parte, sobre os Argilossolos (55,5\%) e os Gleissolos $(44,4 \%)$.

Tabela 2 - Distribuição das tipologias de sítios arqueológicos nas diferentes formações pedológicas

\begin{tabular}{|c|c|c|c|c|c|c|c|c|}
\hline \multirow{3}{*}{ Tipos de Solos } & \multicolumn{6}{|c|}{ Sítios arqueológicos } & \multirow{3}{*}{ Total } & \multirow{3}{*}{ (\%) } \\
\hline & \multicolumn{2}{|c|}{ Guarani } & \multicolumn{2}{|c|}{ Sambaqui } & \multicolumn{2}{|c|}{ Lítico } & & \\
\hline & Registros & $(\%)$ & Registros & $(\%)$ & Registros & $(\%)$ & & \\
\hline Neossolos (AQd) & 16 & 50,0 & 3 & 25,0 & 0 & 0 & 19 & 35,8 \\
\hline Neossolos (AMa4) & 2 & 6,3 & 4 & 33,3 & 0 & 0 & 6 & 11,3 \\
\hline Argilossolo (PEa7) & 9 & 28,1 & 0 & 0 & 0 & 0 & 9 & 17 \\
\hline Argilossolo (PVd1) & 1 & 3,1 & 0 & 0 & 4 & 44,4 & 5 & 9,4 \\
\hline Argilossolo (PVa22) & 0 & 0 & 0 & 0 & 1 & 11,1 & 1 & 1,9 \\
\hline Dunas (D) & 4 & 12,5 & 5 & 41,7 & 0 & 0 & 9 & 17 \\
\hline Gleissolo (HGPd5) & 0 & 0 & 0 & 0 & 4 & 44,4 & 4 & 7,5 \\
\hline Total & 32 & 100 & 12 & 100 & 9 & 100 & 53 & 100 \\
\hline
\end{tabular}

Fonte: Elaborada pelos autores. 
A relação entre a distribuição dos sítios arqueológicos e a cobertura vegetal potencial da área estudada encontra-se esboçada na Tabela 3. Observase que $77,4 \%$ dos sítios registrados situam-se em altitudes mais baixas que os $30 \mathrm{~m}$ acima do nível do mar-NMRM, o que coincide com o atual limite de distribuição da Floresta Ombrófila Densa das Terras Baixas, e apenas $24 \%$ em altitudes superiores a $30 \mathrm{~m}$ acima do NMRM, onde inicia o limite de distribuição da Floresta Ombrófila Densa Submontana.

A distribuição das tipologias de sítios nas diferentes fitofisionomias é apresentada na Tabela
3. Os sítios Guarani estão distribuídos, em sua maioria, nas coberturas vegetais relacionadas à formação de Floresta Ombrófila Densa das Terras Baixas-FODTB, com $81,3 \%$, sendo que as formações Submontanas apresentam 18,8\% de sítios. Os Sambaquis predominam sobre contextos com vegetação de Terras Baixas (91,7\%) e os sítios líticos estão distribuídos com certo equilíbrio entre a vegetação de terras baixas $(44,4 \%)$ e submontanas $(56,6 \%)$.

Tabela 3 - Distribuição das tipologias de sítios arqueológicos nas diferentes formações vegetais pré-históricas potenciais, em que: FODTB = Floresta Ombrófila Densa das Terras Baixas; FODTB (MP) = Floresta Ombrófila Densa das Terras Baixas do tipo sobre solos mal drenados (Mata Paludosa); e FODSM = Floresta Ombrófila Densa Submontana

\begin{tabular}{|c|c|c|c|c|c|c|c|c|}
\hline \multirow{3}{*}{$\begin{array}{l}\text { Formação } \\
\text { Florestal }\end{array}$} & \multicolumn{6}{|c|}{ Tipologia } & \multirow{3}{*}{ Total } & \multirow{3}{*}{ (\%) } \\
\hline & \multicolumn{2}{|c|}{ Guarani } & \multicolumn{2}{|c|}{ Sambaqui } & \multicolumn{2}{|c|}{ Líticos } & & \\
\hline & Registros & $(\%)$ & Registros & $(\%)$ & Registros & $(\%)$ & & \\
\hline FODTB & 26 & 81,3 & 11 & 91,7 & 4 & 44,4 & 41 & 77,4 \\
\hline FODSM & 6 & 18,8 & 1 & 8,3 & 5 & 55,6 & 13 & 22,6 \\
\hline FODTB(MP) & 0 & 0 & 0 & 0 & 0 & 0 & 0 & 0 \\
\hline Total & 32 & 100 & 12 & 100 & 9 & 100 & 53 & 100 \\
\hline
\end{tabular}

Fonte: Elaborada pelos autores.

\section{Cultura material e suas possíveis associações arqueológicas}

Os sítios arqueológicos que sofreram algum tipo de intervenção (coleta de superfície e escavação) foram divididos segundo a cultura material que foi encontrada. Apesar da comparação entre sítios escavados e não escavados ser frágil, buscou-se dividilos por categorias formais tipicamente representantes do conhecimento da cultura material da pré-história do Sul do Brasil ${ }^{1}$ (Tabela 4), com o intuito de avançar nas discussões sobre sequências arqueológicas regionais para, posteriormente, analisar os possíveis sistemas de assentamento dos grupos humanos préhistóricos dessa região. As categorias tipológicas são baseadas nas seguintes presenças: Cerâmica: essa categoria baseia-se apenas no conjunto cerâmico associado a grupos Guarani (Figura 5), pois até o momento não foram encontradas cerâmicas de outro tipo na área Norte do projeto AERUM; lascas: estão agrupados os produtos de debitagem unipolar e/ ou bipolar; mão de pilão e/ou pilão: mão de pilão é um instrumento ativo alongado com secção circular ou oval (Figura 4, peça E), e o pilão (almofariz) é considerado parte complementar de uma mão de pilão; quebra-coquinho: suporte rochoso com uma ou várias depressões semiesféricas polidas (Figura 4, peças F-G-H-I); seixo lascado: seixo lascado uni ou bifacialmente (Figura 2, peça A); ponta bifacial: suportes rochosos finamente façonados, bifacialmente relacionados à tradição Umbu (Figura 3).

Dos 53 sítios mapeados na área pesquisada, 19 sítios arqueológicos foram intervencionados, os quais foram divididos entre sítios líticos, concheiros e litocerâmicos e, posteriormente, associados aos possíveis grupos culturais arqueológicos. Dos nove sítios predominantemente líticos identificados, três estão relacionados à tradição Umbu. Essa relação está estabelecida até o momento unicamente pela presença de pontas bifaciais; afinal, apesar dos 
limites de tal associação, o termo "Tradição Umbu" ainda sugere qualquer coisa relacionada a pontas bifaciais no sul e sudeste do Brasil (OKUMURA;
ARAUJO, 2013, 2014). Os demais sítios líticos não apresentaram dados suficientes para alguma correlação arqueológica do ponto de vista cultural.

Tabela 4 - Divisão dos sítios arqueológicos intervencionados por categorias tipológicas da cultura material

\begin{tabular}{|c|c|c|c|c|c|c|c|c|c|c|}
\hline $\begin{array}{l}\text { Sítio } \\
\text { arqueológico }\end{array}$ & $\begin{array}{l}\text { Inter- } \\
\text { venção }\end{array}$ & $\begin{array}{c}\text { Tipo } \\
\text { de Sítio }\end{array}$ & $\begin{array}{c}\text { Associação } \\
\text { Cultural }\end{array}$ & $\begin{array}{c}\text { Cerâ- } \\
\text { mica }\end{array}$ & Lascas & $\begin{array}{c}\text { Mão e/ou } \\
\text { Pilão }\end{array}$ & $\begin{array}{l}\text { Quebra- } \\
\text {-Coquinho }\end{array}$ & $\begin{array}{c}\text { Seixo } \\
\text { Lascado }\end{array}$ & $\begin{array}{c}\text { Ponta } \\
\text { Bifacial }\end{array}$ & Total \\
\hline SC-MJ-01 & Coleta & Lítico & - & & & 3 & 1 & & & 4 \\
\hline SC-MJ-02 & Coleta & Lítico & - & & 1 & 2 & & & & 3 \\
\hline SC-MJ-03 & Coleta & Lítico & - & & 20 & & & 1 & & 21 \\
\hline SC-MJ-04 & Coleta & Lítico & - & & 1 & & & & & 1 \\
\hline SC-MJ-05 & Coleta & Lítico & - & & 3 & & & & & 3 \\
\hline SC-MJ-06 & Coleta & Lítico & Umbu & & 3 & 1 & & & 2 & 6 \\
\hline SC-MJ-07 & Coleta & Lítico & Umbu & & & 1 & & & 15 & 16 \\
\hline SC-MJ-09 & Coleta & Lítico & - & & & & & & & 0 \\
\hline SC-MJ-10 & Coleta & Lítico & Umbu & & & & & & 30 & 30 \\
\hline SC-IÇ-06 & Escavação & Concheiro & Sambaqui & & 33 & 2 & 13 & & & 48 \\
\hline SC-IÇ-01 & Escavação & Concheiro & $\begin{array}{l}\text { Sambaqui/Jê } \\
\text { Meridional }\end{array}$ & & 24 & 60 & 198 & 7 & & 289 \\
\hline SLF & Escavação & Concheiro & $\begin{array}{l}\text { Sambaqui/Jê } \\
\text { Meridional }\end{array}$ & & 26 & & 3 & & & 29 \\
\hline EILE & Escavação & Litocerâmico & Guarani & 575 & 17 & & & & & 592 \\
\hline CLE & Escavação & Litocerâmico & Guarani & 3913 & 26 & & & & & 3939 \\
\hline LML & Escavação & Litocerâmico & Guarani & 352 & 2 & & & & & 354 \\
\hline ML1 & Escavação & Litocerâmico & Guarani & 10298 & 31 & & & & & \\
\hline ML3 & Escavação & Litocerâmico & Guarani & 1359 & 13 & & & & & 1372 \\
\hline MLA & Escavação & Litocerâmico & Guarani & 1008 & 19 & & & & & 1027 \\
\hline Total & & & & 17505 & 219 & 69 & 215 & 8 & 47 & \\
\hline
\end{tabular}

Fonte: Elaborada pelos autores.

Levando-se em consideração a divisão apresentada na Tabela 4, os sítios concheiros apresentam maior variabilidade formal nos conjuntos líticos em relação aos demais sítios. Essa relação pode estar relacionada à escavação que os mesmos sofreram, originando maior quantidade de material. No entanto, os quebra-coquinhos, mãos de pilão e pilão e algum indício de indústria sobre seixos aparecem nesse tipo de sítio. As indústrias líticas desse tipo de sítio apresentam distinções nos instrumentos polidos, levando-se em consideração os horizontes cronológicos apresentados (Tabela 5).

Os sítios litocerâmicos, diretamente associados a sítios Guarani, apresentam a maior uniformidade, levando-se em consideração os aspectos materiais aqui apresentados, uma vez que, embora o material cerâmico seja o que caracteriza esse tipo de sítio do ponto de vista material (Figura 5), fica evidente que as indústrias líticas sobre lascas predominam nesse conjunto de sítios, excluindo, até o momento, toda a variabilidade regional ligada a indústrias líticas polidas e de redução bifacial.

Nesse contexto arqueológico apresentado, foram escavados oito sítios arqueológicos (três concheiros e cinco litocerâmicos), nos quais foram realizadas 16 datações que podem representar três grupos culturais entre 3.697-230 anos AP (Tabela 5). 
Tabela 5 - Datações arqueológicas obtidas até o momento na área Norte do Projeto AERUM. As datas dos sítios SCIÇ-06 e SC-IÇ-01 foram calibradas pelo programa OxCal v4.2.3 r:5 IntCal13 atmospheric curve (BRONK RAMSEY; SCOTT; VAN DER PLICHT, 2013). Sambaqui do Geraldo (SC-IÇ-06), Sambaqui Içara 01 (SC-IÇ-01), Sambaqui Lagoa dos Freitas (SLF), Acampamento Cemitério Lagoa dos Esteves (CLE), Aldeia Lagoa Mãe Luzia (LML), Aldeia Mãe Luzia 1 (ML1), Aldeia Mãe Luzia 3 (ML3), Aldeia Mirante da Lagoa (AML)

\begin{tabular}{|c|c|c|c|c|c|c|c|}
\hline Sítio & Ambiente & $\begin{array}{l}\text { Afiliação } \\
\text { Cultural }\end{array}$ & $\begin{array}{c}\text { Equipe } \\
\text { Responsával }\end{array}$ & Amostra & Método & Datação (AP) & $\begin{array}{l}\text { Cod. } \\
\text { Laboratório }\end{array}$ \\
\hline SC-IÇ-06 & D. Holocênicas & Sambaqui & IAP-Unissinos/1992 & Carvão & $\mathrm{C} 14$ & $3.697-3.377 \mathrm{cal}$ & BETA 197606 \\
\hline SC-IÇ-01 & D. Holocênicas & $\begin{array}{c}\text { Sambaqui Tardío/Jê } \\
\text { Meridional }\end{array}$ & IAP-Unissinos/1992 & Carvão & $\mathrm{C} 14$ & $1.532-1.320 \mathrm{cal}$ & BETA 72196 \\
\hline SC-IÇ-01 & D. Holocênicas & $\begin{array}{c}\text { Sambaqui Tardío/Jê } \\
\text { Meridional }\end{array}$ & IAP-Unissinos/1992 & Carvão & $\mathrm{C} 14$ & $1.427-1.184 \mathrm{cal}$ & BETA 72197 \\
\hline SLF & D. Holocênicas & $\begin{array}{c}\text { Sambaqui Tardío/Jê } \\
\text { Meridional }\end{array}$ & LAPIS-UNESC/2015 & Carvão & $\mathrm{C} 14$ & $1.315-1.275 \mathrm{cal}$ & BETA 426824 \\
\hline SLF & D. Holocênicas & $\begin{array}{c}\text { Sambaqui Tardío/Jê } \\
\text { Meridional }\end{array}$ & LAPIS-UNESC/2014 & Carvão & $\mathrm{C} 14$ & $1.360-1.290 \mathrm{cal}$ & BETA 403222 \\
\hline SLF & D. Holocênicas & $\begin{array}{c}\text { Jê Meridional/ } \\
\text { Guarani }\end{array}$ & LAPIS-UNESC/2014 & Carvão & $\mathrm{C} 14$ & 485-305cal & BETA 403221 \\
\hline SLF & D. Holocênicas & $\begin{array}{l}\text { Jê Meridional/ } \\
\text { Guarani }\end{array}$ & LAPIS-UNESC/2014 & Carvão & $\mathrm{C} 14$ & $495-320 \mathrm{cal}$ & BETA 403220 \\
\hline SLF & D. Holocênicas & $\begin{array}{l}\text { Jê Meridional/ } \\
\text { Guarani }\end{array}$ & LAPIS-UNESC/2015 & Carvão & $\mathrm{C} 14$ & $240-230 \mathrm{cal}$ & BETA426825 \\
\hline CLE & D. Pleistocênicas & Guarani & IPAT-UNESC/1999 & Cerâmica & $\mathrm{TL}$ & $610+-60$ & UNESP/2000 \\
\hline LML (Mancha 2) & D. Pleistocênicas & Guarani & IPAT-UNESC/1999 & Cerâmica & $\mathrm{TL}$ & $720+-70$ & UNESP/2000 \\
\hline ML1 (F. Mancha) & D. Pleistocênicas & Guarani & LAPIS-UNESC/2013 & Carvão & $\mathrm{C} 14$ & $500-310 \mathrm{cal}$ & BETA366854 \\
\hline ML1 (F. Mancha) & D. Pleistocênicas & Guarani & LAPIS-UNESC/2013 & Carvão & $\mathrm{C} 14$ & $500-310 \mathrm{cal}$ & BETA366853 \\
\hline ML1 (Mancha 3) & D. Pleistocênicas & Guarani & LAPIS-UNESC/2013 & Carvão & $\mathrm{C} 14$ & 500-311cal & BETA366851 \\
\hline ML1 (Mancha 2) & D. Pleistocênicas & Guarani & LAPIS-UNESC/2013 & Carvão & $\mathrm{C} 14$ & $480-301 \mathrm{cal}$ & BETA366850 \\
\hline ML3 & D. Pleistocênicas & Guarani & LAPIS-UNESC/2014 & Carvão & $\mathrm{C} 14$ & $490-315 \mathrm{cal}$ & BETA403218 \\
\hline AML & D. Pleistocênicas & Guarani & LAPIS-UNESC/2014 & Carvão & $\mathrm{C} 14$ & $495-320 \mathrm{cal}$ & BETA403217 \\
\hline
\end{tabular}

Fonte: Elaborada pelos autores.

Observando as datas, admite-se que os sítios arqueológicos investigados formam um conjunto de ocupações diferenciadas em uma pequena escala espacial e temporal. Os resultados indicam que a parte Norte do território do projeto AERUM foi ocupada por grupos humanos com hábitos de caça, pesca e coleta e, posteriormente, por agricultores ceramistas, em um quadro arqueologicamente e cronologicamente conhecido no contexto regional (DIAS, 2007; DEBLASIS; GASPAR, 2009; GIANNINI et al., 2010; MILHEIRA, 2010; MILHEIRA; DEBLASIS, 2013).

O conjunto de datas aqui apresentado permite, pela primeira vez, indicar uma sequência cronológica regional, em que, até o momento, se observam três horizontes diferenciados e suas possíveis associações culturais: 3.697-3.377 anos AP (Sambaquis Plenos); 1532-1184 anos AP (Sambaquis
Tardios e/ou Jê Meridionais) e 720-230 anos AP (Guarani).

As datas obtidas indicam que os grupos Sambaquis foram os primeiros a chegar nesse território, talvez sendo um reflexo do período de apogeu social desse grupo na região de Laguna, $50 \mathrm{~km}$ ao Norte da área do AERUM (DEBLASIS; GASPAR, 2009), onde o Sambaqui do Geraldo representaria essa expansão no território do AERUM. Os Sambaquis Içara 01 e Lagoa dos Freitas podem representar Sambaquis Tardios ou sinais dos primeiros grupos Jê-Meridionais que migraram para o litoral de Santa Catarina (SCHMITZ, 1999; FARIAS; SCHMITZ, 2012). Outra hipótese plausível estaria associada a uma mudança cultural ocorrida do contato entre os diferentes grupos chegados a essa parte do litoral. 
Os sítios litocerâmicos associados ao grupo Guarani apresentam um quadro cronológico mais homogêneo, o qual demonstra que a chegada deles ao litoral aconteceu ao menos 200 anos antes da chegada dos colonizadores europeus na região. Corroborando esta pesquisa, dados apresentados recentemente por Bonomo et al. (2015), indicam que o litoral Sul do Brasil foi uma das últimas áreas a serem colonizadas pelos grupos Guarani, aproximadamente entre 1.000 e $1780 \mathrm{AD}$.

A incógnita cronológica está relacionada aos sítios associados à tradição Umbu. Apesar de esses sítios não apresentarem cronologia na pequena área de estudo, são considerados os primeiros grupos a povoarem o Brasil Meridional há cerca de 11.000 anos AP (BUENO; DIAS; STEELE, 2013; BUENO; DIAS, 2015), permanecendo em algumas regiões até o século XVII (DIAS, 2003). Assim sendo, abre-se uma interessante questão sobre os sistemas de assentamento realizados nessa região: em uma área de $286 \mathrm{~km}^{2}$ (26 x $11 \mathrm{~km}$ ), qual seria a relação cronológica dos sítios arqueológicos relacionados aos grupos da tradição Umbu e aos grupos Sambaquis, Jê-Meridionais e Guarani, haja vista a longa duração dessa ocupação para algumas regiões de Mata Atlântica no Sul do Brasil?

\section{Discussão}

Com base nos registros obtidos na área de estudo, procurou-se, primeiramente, sob a ótica ambiental, analisar a distribuição dos sítios na paisagem e sua associação às formações geológicas, às feições geomorfológicas, aos recursos hídricos, aos tipos de solos e aos recursos bióticos, buscando extrair informações que possam dar suporte à interpretação das razões pelas quais os diferentes sítios arqueológicos se distribuem de forma diferenciada em relação às características físicas e bióticas da área.

Dos 13 tipos de solos, e suas variantes, descritos para a área de pesquisa, em sete foram registrados sítios arqueológicos, os quais foram classificados em quatro tipos: Neossolos, Argilossos, Gleissolos e Dunas. Os sítios arqueológicos se encontram majoritariamente nos Neossolos (areia quartzosa e areia quatzosa marinha), com cerca de
$60 \%$. Os Neossolos estão diretamente associados às formações sedimentares litorâneas, sendo que esse dado está em consonância com a distribuição dos sítios pelas formações litológicas.

Dos três tipos de formações vegetais précoloniais existentes na área de estudo, apenas em duas aparecem sítios arqueológicos, sendo essas associadas às cotas mais elevadas. Assim sendo, foi tomada a cota altimétrica $2,0 \mathrm{~m}$ como a cota de limite altitudinal dos terrenos que atualmente estão sob a influência do regime de marés na planície costeira, ou seja, nos locais que estão abaixo da cota altimétrica 2,0 $\mathrm{m}$ se faz sentir a influência das marés e o terreno fica inundado pela água salgada (Figura 1).

Pensando em locais de assentamento préhistórico, onde a cobertura vegetal é levada em consideração, observa-se que, percentualmente, a Floresta Ombrófila Densa das Terras Baixas, com $77,4 \%$, foi eleita como local privilegiado nesse quesito. A Floresta Ombrófila Densa Submontana aparece em segundo lugar, porque apresenta, percentualmente, considerável expressividade, com $22,6 \%$. Nenhum sítio arqueológico foi registrado na área de abrangência da Floresta Ombrófila Densa das Terras Baixas sobre solos mal drenados (Mata Paludosa), indicando que, provavelmente, os padrões de assentamento das populações pré-históricas não eram compatíveis com as características ambientais oferecidas por essa formação florestal, visto que nela o lençol freático aflora e fica sobre a superfície do solo por longos períodos, como na época de enchentes ou de marés altas. De outra forma, como o relevo da paisagem do extremo sul catarinense, especialmente na área Norte do AERUM, sofre variações, é provável que as populações pré-históricas tenham tido a possibilidade de escolher os locais mais secos e distantes das zonas mais baixas como locais de assentamentos mais fixos.

Apesar de, percentualmente, a maior parte dos sítios Líticos estarem assentados na formação litológica Estrada Nova (Pen), eles apresentaram uma distribuição heterogênea no quesito litologia, aparecendo em quatro formações litológicas. Um aspecto interessante da distribuição geográfica dos sítios líticos registrada é que a maior parte se encontra preferencialmente distante do litoral, em cotas altas (acima dos $20 \mathrm{~m}$ ) e próximo dos afloramentos rochosos associados à formação Serra Geral. 
Dos nove sítios líticos encontrados, três apresentaram pontas bifaciais relacionadas, arqueologicamente, à tradição Umbu. Se assim forem considerados, é possível hipotetizar que eles são os representantes materiais dos primeiros grupos humanos que chegaram ao litoral do extremo Sul Catarinense; no entanto, a inexistência de datações e escavações desses sítios arqueológicos impossibilita sua compreensão diacrônica nessa área. O que se pode afirmar é que nas nove escavações realizadas nos demais sítios (concheiros e litocerâmicos) não foram encontrados instrumentos com façonagem bifacial, mas há uma recorrência de instrumentos façonados bifacialmente (pontas bifaciais) nessa área, indicando ser, até o momento, um conjunto tecnológico independente dos encontrados nos sítios concheiros e litocerâmicos da região (Figura 2).

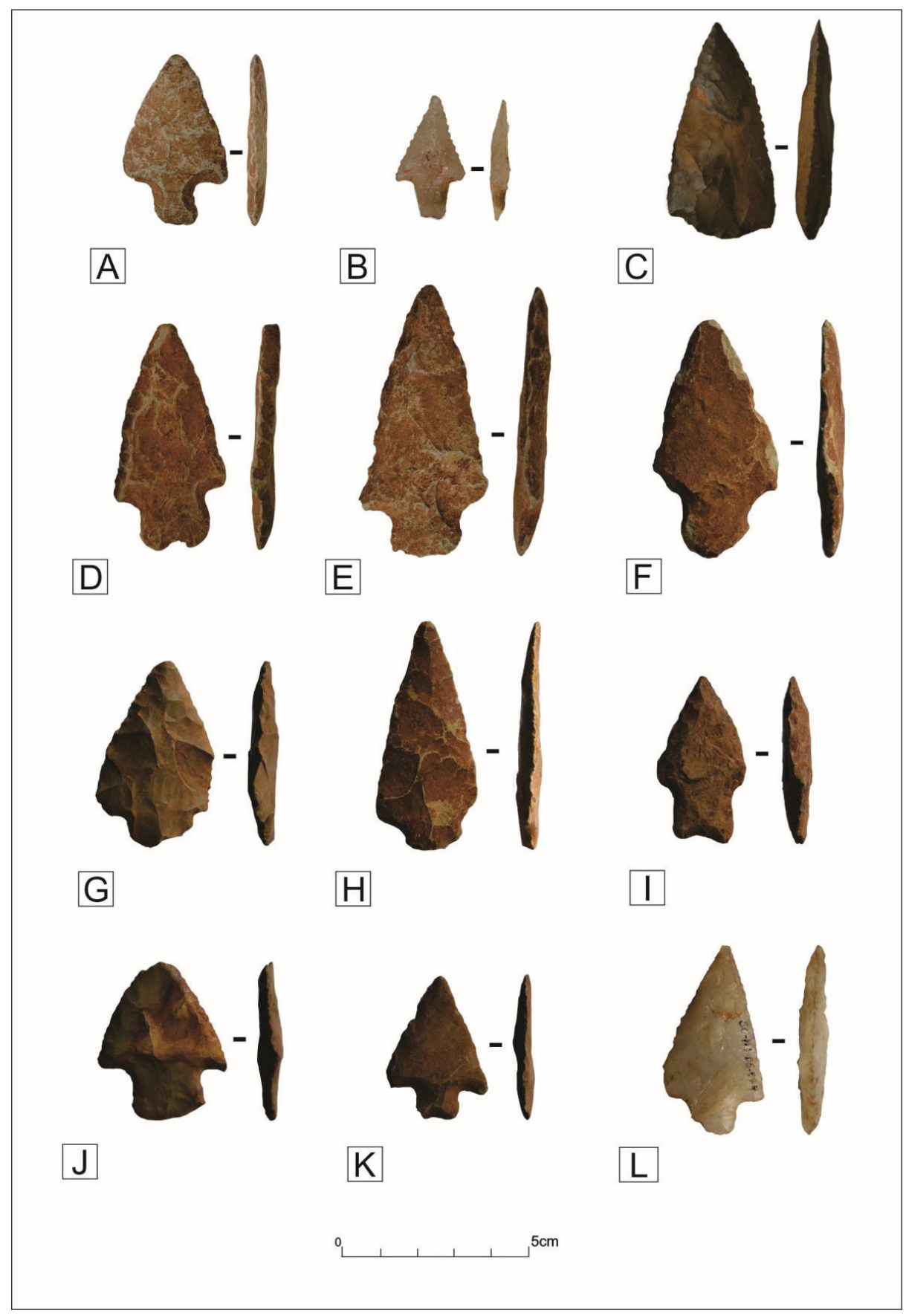

Figura 2 - Pontas bifaciais relacionadas à tradição Umbu presentes na área Norte do território do AERUM: Peças A - E sítio SC-MC-07; Peças F - K sítio SC-MJI-010; Peça L sítio SC-MJ-06 Fonte: Elaborada pelos autores. 
Os sítios concheiros estão assentados preferencialmente na formação litológica LagunaBarreira Holocênica (QHb) e em solo dunar, sendo essa uma característica uniforme dos padrões de assentamento dos sítios dessa tipologia, os quais foram expostos em ampla bibliografia já citada. A predominante distribuição dos concheiros no topo das formações sedimentares holocênicas os relacionam diretamente com as formações da Floresta Ombrófila Densa das Terras Baixas. Esse é o parâmetro ambiental que mais caracteriza ecologicamente o assentamento desse grupo, levando-se em consideração os aspectos geológicos, pedológicos e fitofisiológicos.

Os sítios concheiros (relacionados aos Sambaquis), do ponto de vista cronológico e material, podem ser divididos em dois horizontes:

- Horizonte 1 (3.697-3.377 cal anos AP): Esse período está representado pelo sítio Sambaqui do Geraldo, onde se encontraram indústrias ósseas, em conchas, e líticas. O conjunto lítico com 1.923 peças, das quais cerca de $80 \%$ foram indicadas como seixos sem modificação (ROGGE; ARNT, 2006), pode, até o momento, ser caracterizado como uma indústria baseada na técnica de polimento com instrumentos ativos e passivos (LAMINGEMPERAIRE, 1967). Os instrumentos ativos apresentam morfologia alongada, com alto grau de polimento, principalmente nos gumes. Uma característica interessante é uma padronização na parte preensiva dos instrumentos alongados com dois sulcos abrasivos laterais (reentrâncias) (Figura 3: J-L-M-N). Aparecem, consideravelmente, pequenos instrumentos alongados com secções quadrangulares (Figura 3: A-F). Outra categoria de instrumentos (Figura 2: P-Q-R) apresenta marcas de percussão, abrasão e polimento, indicando serem instrumentos com longo estágio técnico, onde, a forma do suporte original foi bastante modificada. Essa última categoria de instrumentos está em consonância com as características multifuncionais de alguns instrumentos de Sambaquis indicados por Alves (2010), Belém e Deblasis (2015). As matérias primas predominantes são as rochas ígneas (basalto e diabásio).

- Horizonte 2 (1.532-1.184 cal AP): Esse período está representado pelos sítios Sambaqui Içara 01 (1.532-1.184 cal AP) e o horizonte mais antigo do sítio Sambaqui Lagoa dos Freitas (1360-1275 cal). Nesse período, foram identificadas indústrias ósseas e líticas. A indústria óssea é representada por sete pontas ósseas (uma em osso de ave e as outras indeterminadas) e um esporão de arraia polido. A indústria lítica é representada por 3.764 peças no Sambaqui Içara 01 aproximadamente $75 \%$ do material lítico foi considerado natural (SCHMITZ, 1999) - e 90 Peças no Sambaqui Lagoa dos Freitas. Nesse horizonte, observa-se a ocorrência de indústria sobre seixos associada à debitagem direta unipolar (Figura 4: peças A-B). Uma característica desse período é o basalto em forma de seixo como suporte e matériaprima predominante. Os instrumentos mais característicos (do ponto de vista formal) são os de tipo alongado com secção circular (mão de pilão - Figura 4: peça E) e os suportes rochosos com depressões semiesféricas (quebra-coquinhos - Figura 4: peças F-G-H-I). Este último apresenta, nesse horizonte cronológico, considerável variabilidade morfológica, dimensional, de matéria-prima e de suporte utilizado, indicando possíveis funções diferenciadas, com depressões circulares e ovaladas, rasas e profundas. A variabilidade morfotécnica dos "quebra-coquinhos" já foi observada na região do Sul do Rio Grande do Sul (GLUCHY; SALLES, 2014). 


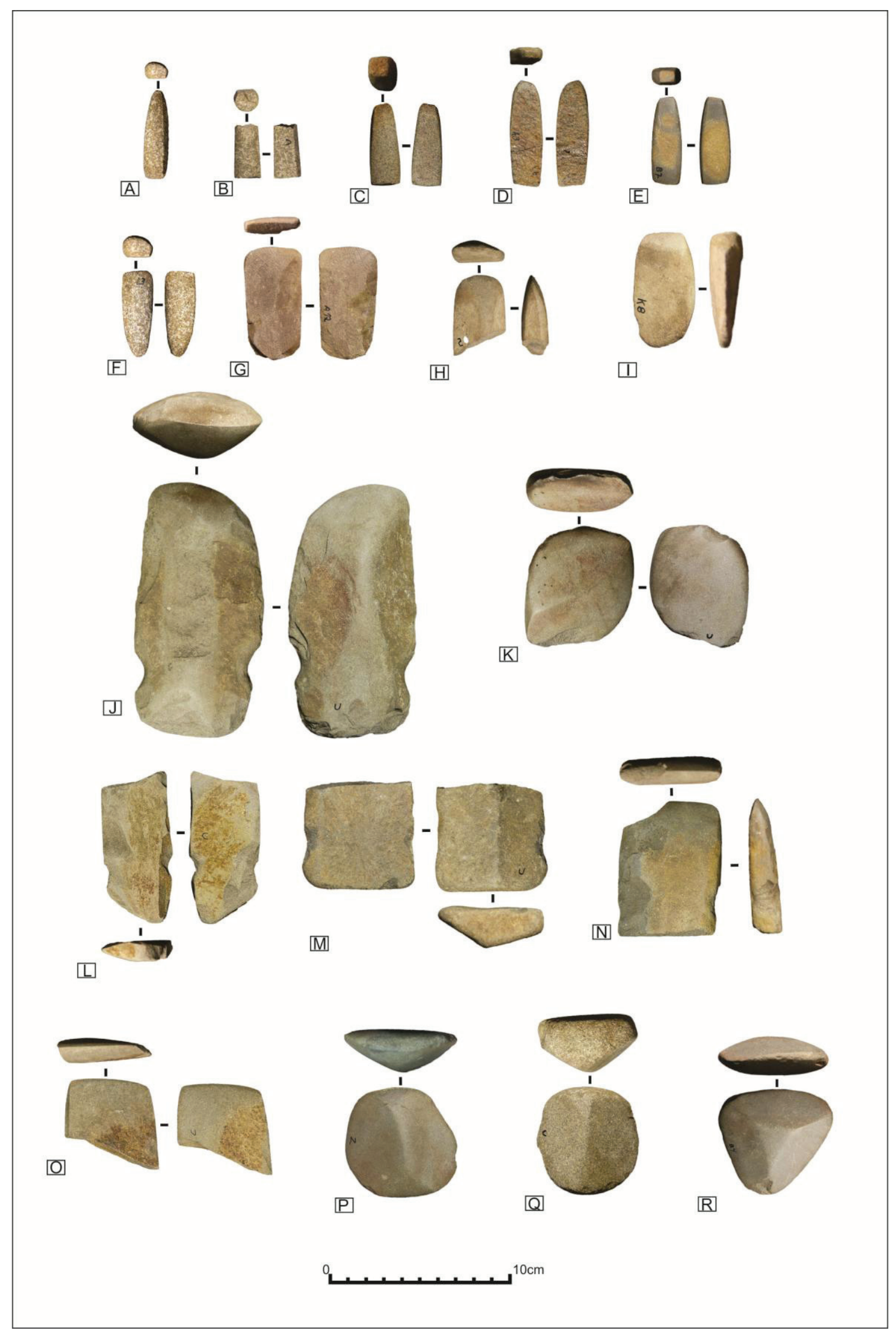

Figura 3 - Conjunto de artefatos líticos do Sambaqui do Geraldo, o qual representa o Horizonte 1 Fonte: Elaborada pelos autores. 


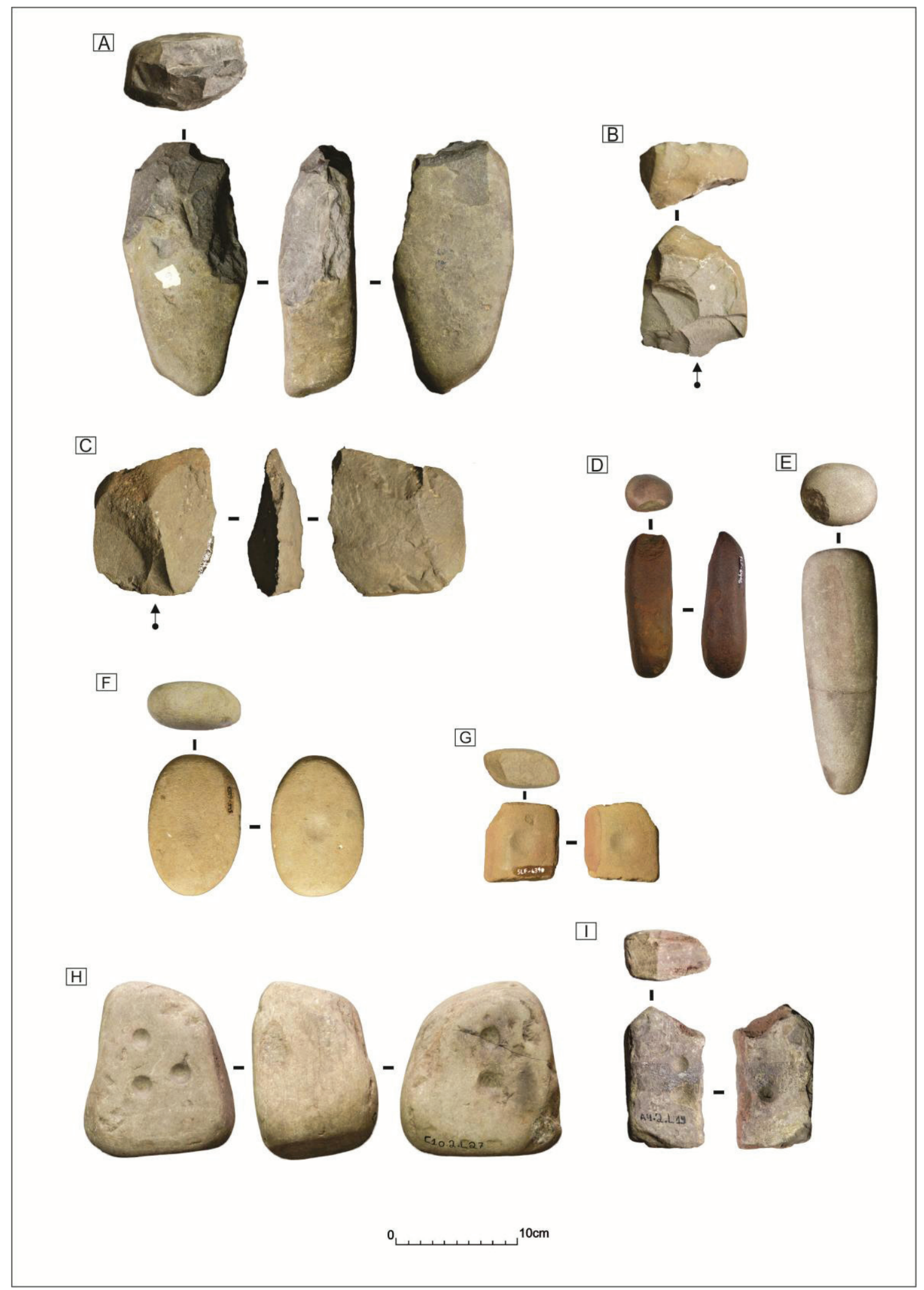

Figura 4 - Conjunto de artefatos líticos do Horizonte 2: peças do sítio Sambaqui Içara 01: A, B, E, H e I; peças do Sítio Sambaqui Lagoa dos Freitas: C, D, F, G

Fonte: Elaborada pelos autores. 
Os sítios Guarani, na área estudada, estão majoritariamente localizados sobre a formação Laguna-Barreira Pleistocênica (QPb - Depósitos Praiais Marinhos e Eólicos), representando 65,6\% dos sítios dessa tipologia. Os sítios localizados em menor quantidade nas demais formações litológicas indicam que os grupos Guarani elegeram como zona de ocupação preferencial os espaços delimitados pelas dunas Pleistocênicas. No entanto, foram encontrados sítios em outras quatro formações litológicas, corroborando a hipótese de que as aldeias Guarani - relacionadas a assentamentos fixos - localizam-se nas partes elevadas da região litorânea - formada por solos arenosos - e os sítios sazonais (acampamentos) permeiam espacialmente toda a região aqui estudada (CAMPOS et al., 2013; CAMPOS, 2015). Sítios de coleta de materiais específicos -aliados a locais de roça, caça e pesca -, afastados das aldeias centrais, são características básicas do sistema de assentamento Guarani salientadas por Noelli (1993) e Soares (1997).

Os sítios Guarani estão distribuídos, em sua maioria, nas coberturas vegetais relacionadas à formação de Floresta Ombrófila Densa das Terras Baixas, com $81,3 \%$, sendo que a formação Submontana detém apenas $18,8 \%$ dos sítios, sugerindo que os grupos Guarani escolhiam como local de assentamentos mais fixos as zonas vegetais das Terras Baixas e como local de coleta de materiais com formação de sítios sazonais as zonas de vegetação Submontana e as zonas da praia, não ficando clara a relação dos povos Guarani com as áreas interiores dessa área.

Aliada a um diversificado complexo morfológico cerâmico (Figura 5), a indústria lítica dos sítios arqueológicos litocerâmicos Guarani é permeada majoritariamente por duas matériasprimas: arenitos e calcedônias. As peças em arenito são fragmentos com sulcos polidos conhecidos tipologicamente como afiadores/calibradores (LAMING- EMPERAIRE, 1967). No entanto, essa categoria de instrumento apresenta diferenciada espessura nos sulcos, indicando que materiais de diferentes espessuras foram utilizados com ela. A calcedônia apresenta uma indústria de produção de lascas, as quais, provavelmente, foram usadas diretamente, sem retoque (Figura 6). A relação entre sítios Guarani da faixada atlântica e instrumentos líticos em arenito e calcedônia foi observada por Milheira (2011) em sítios litorâneos da margem sudoeste da Laguna dos Patos/RS, indicando um possível padrão na organização tecnológica das indústrias líticas dos grupos Guarani da planície costeira meridional, que se baseiam principalmente nessas duas matérias-primas.

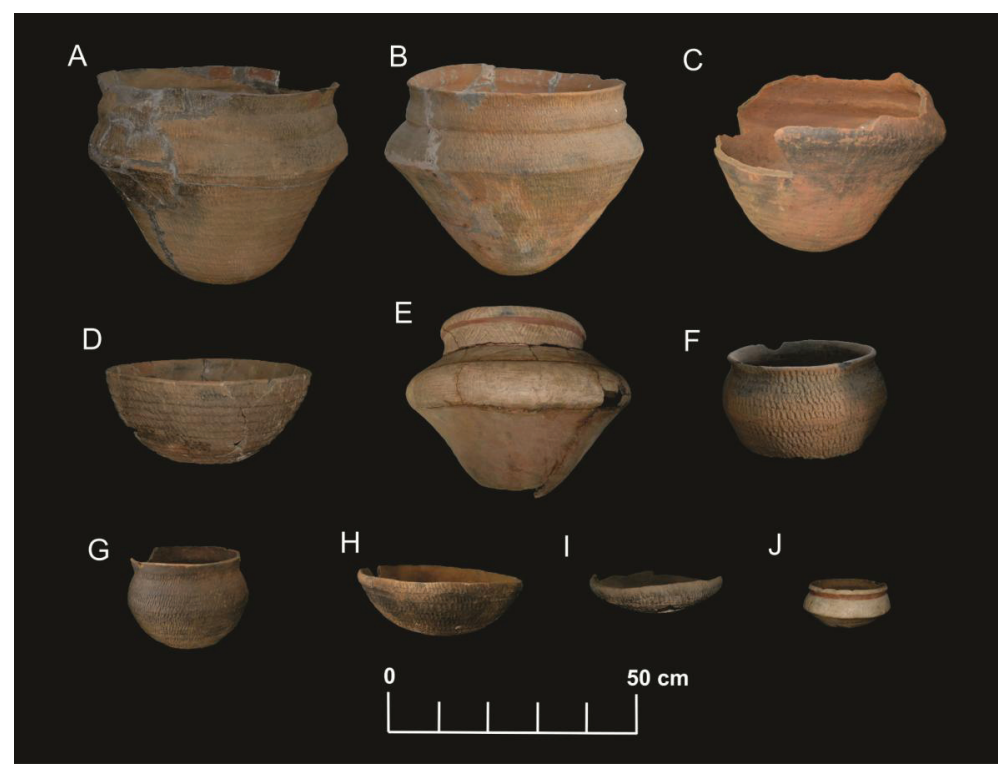

Figura 5 - Conjunto de formas cerâmicas inteiras encontradas na área Norte do projeto AERUM: Vasilha A, B, D e F - comunidade de Boa Vista, Balneário Rincão; C - Morro dos Conventos (SC-ARA-051); E e I - Içara (Luquinha do Zé Pequeno); G - Lagoa dos Esteves - Rincão; H e J - Balneário Gaivota Fonte: Elaborada pelos autores. 
Um aspecto em aberto é a problemática dessas ocupações humanas relacionadas ao litoral: os grupos imigrantes, possivelmente do interior, tendo atingido a costa, orientaram sua economia para os recursos aquáticos? Que influência esse ambiente teria infligido aos grupos humanos? Isso se demonstra principalmente pela constatação de estruturas conchíferas associadas a grupos Guarani
(CAMPOS, 2015). Essas questões de resiliência dos grupos humanos ao ambiente litorâneo já foram salientadas por Colonese et al. (2014). Questiona-se, desse modo, se os grupos não Sambaquianos, tendo atingido a costa, teriam orientado sua economia para os recursos aquáticos. Se sim, indaga-se: Que influência a cultura material teria sofrido?

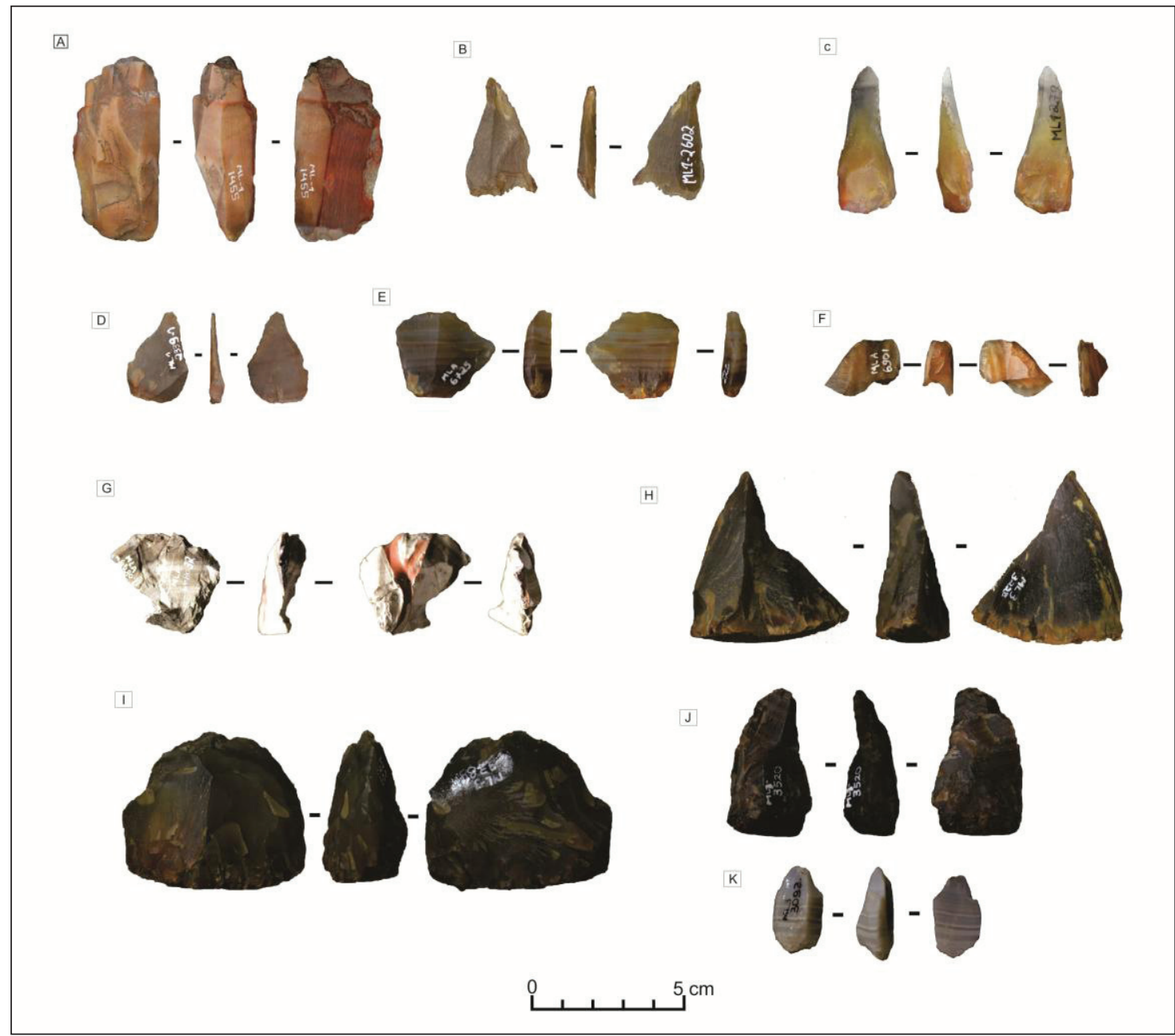

Figura 6 - Lascas de Calcedônia típicas de sítios Guarani: Peças A - D sítio ML-1; peças E-G sítio MLA; peças H-K sítio ML-3

Fonte: Elaborada pelos autores.

\section{Considerações finais}

Com base no conjunto dos dados arqueológicos, físicos, paleoambientais e cronológicos aqui apresentados, é proposta, pela primeira vez, uma sequência arqueológica regional, dividida em três horizontes cronológicos.

Até o momento, as ocupações humanas na porção Norte da região do AERUM ocorreram posteriormente ao último máximo eustático documentado para a costa do Brasil há 5.100 anos AP (ANGULO et al., 2006; CANCELLI, 2012; GIANNINI et al., 2007; SUGUIO et al., 1985; VILLWOCK; TOMAZELLI, 1998), ou seja, um contexto de regressão marinha aliado ao estabelecimento e expansão da Floresta Tropical sobre as zonas recentemente emersas. 
Horizonte 1: estabelecido até o momento entre 3.697-3.377 cal anos AP, esse período está associado ao fim da fase paleoambiental 2 (VAL, 2015), que se caracteriza como um ambiente com gradual aumento de vegetação herbáceo-arbustiva. As áreas mais baixas se tornaram pantanosas, com a existência de banhados costeiros e diversos corpos lagunares nas zonas mais profundas. Aliados a esse contexto paleoambiental os grupos humanos desse período utilizaram as espécies Mesodesma mactroides Reeve, 1854 (marisco branco) e Donax hanleyanus Philippi, 1847 (moçambique) como preferenciais na composição das estruturas conchíferas, associadas às faunas aquáticas e ao rico material orgânico. Ocupavam as áreas secas no topo das dunas holocênicas, entre as Lagoas em plena formação e o Mar, sendo esse, até o momento, um aspecto definitivo dessa ocupação. A fauna explorada era diversificada, com maior abundância e diversidade de espécies ecologicamente associadas a hábitos costeiros, marítimos e água doce, complementarizados por considerável diversidade de mamíferos terrestres. Essa diversidade faunística indica que os mesmos desenvolviam práticas de pesca em lagoas, estuários e rios, além de incursões na praia, a fim de predar mamíferos marinhos (Arctocephalus sp. G. SaintHilaire \& Cuvier, 1826 - lobo marinho) e aves (Spheniscus magellanicus (d'Orbigny \& Lafresnaye, 1837) - pinguim-de-magalhães). No entanto, as espécies de mamíferos associadas e ambientes florestais fechados (C. paca - paca, T. pecari - porco do mato, Procyon cancrivorus Cuvier, 1798 - mão pelada) indicam técnicas de caça associadas ao interior do território.

As indústrias líticas também indicam essa relação com o interior, haja vista que as matériasprimas predominantes (basalto e diabásio) não afloram nessa parte do litoral. A técnica predominante é o polimento, com instrumentos ativos alongados, possivelmente encabados, que indicam associação a trabalhos pesados. Além da pedra, eram elaborados artefatos em ossos e conchas, tais como anzóis, pontas (feitas de ossos de ave e no esporão da arraia e bagre).

Horizonte 2: cronologicamente estabelecido entre 1.532-1.184 AP, esse período está relacionado com a fase paleoambiental 3 (VAL, 2015). Associado ao aumento da umidade, caracteriza-se pela expansão da floresta, com táxons arbóreos característicos da Floresta Ombrófila Densa de Terras Baixas. A fixação da floresta nessa área influenciou a diminuição dos corpos d'água e os terrenos brejosos, afetando consequentemente o tamanho dos corpos lagunares. Nesse período, vê-se o mesmo processo de acúmulo de conchas baseadas nas espécies $M$. mactroides (marisco branco) e D. hanleyanus (moçambique). Há uma especialização na pesca das espécies Genidens sp. (bagres) e M. furnieri (corvina), aliada à captura de mamíferos terrestres, com maior abundância para os taiaçuídeos (porco do mato), T. terrestris (anta) e cervídeos (veados). Os grupos humanos enterravam seus mortos em sítios concheiros específicos de forma primária e secundária; a disposição dos corpos indica procedimentos diferenciados de sepultamento. Os indivíduos apresentaram idades máximas entre 45 anos, não se percebendo, do ponto de vista patológico, grandes traumatismos, a não ser Artrites e Artrose. A saúde bucal indicou pouco consumo de carboidratos nesse horizonte (SCHMITZ et al., 1999).

A indústria lítica indica certa associação com o Horizonte 1, no entanto, com algumas categorias diferenciadas. É evidente a importância quantitativa dos instrumentos conhecidos como mão de pilão e quebra-coquinho, principalmente nos sepultamentos, e a ocorrência de indústria sobre seixos associada à debitagem direta unipolar com predomínio de Basalto em forma de seixo como matéria-prima preferencial.

Horizonte 3: estabelecido até o momento entre os 720-301 anos AP, esse período indica uma notória ruptura na organização da ocupação do território, com sítios diferenciados (aldeias e acampamentos) e o aparecimento da tecnologia cerâmica (Figura 4). Diretamente associados aos povos Guarani, esses grupos escolheram as partes mais altas e férteis do litoral para se estabelecer (Dunas pleistocênicas). Um aspecto interessante desse período é a continuidade do fenômeno de acúmulo de conchas por esses grupos no litoral, no entanto, de dimensões bem menores que nos períodos anteriores.

Nesse horizonte, compreende-se a diminuição da importância da indústria lítica, no entanto, suas características são as mais homogêneas. As peças 
apresentam pequenas dimensões e estão relacionadas à indústria de lascas associadas à Calcedônia e aos instrumentos passivos com sulcos polidos feitos em Arenito Botucatu e conhecidos tipologicamente como calibradores.

Partindo da premissa de que nessa pequena área $(26 \mathrm{x} 11 \mathrm{k} \mathrm{m})$ os oito sítios escavados (Sambaqui e Guarani) não apresentaram instrumentos com façonagem bifacial associados à tradição Umbu, seria plausível hipotetizar que esse sistema técnico estaria associado a um período de ocupação anterior, haja vista que as ocupações dos últimos 4.000 anos associadas aos Sambaquis, Je-Meridionais e Guarani nesse território parecem ser contínuas até a chegada dos colonizadores.

Sendo assim, admite-se que os sítios arqueológicos investigados formam um conjunto de ocupações sobrepostas na paisagem e que o território do extremo sul catarinense parece ter sido um local de contato entre grupos culturalmente diferentes, não sendo ainda claro o resultado arqueológico desses possíveis contatos.

Agradecimentos: Agradecemos aos amigos arqueólogos Antoine Lourdeau e Francisco Noelli pelas valiosas críticas, sugestões e inserções que tornaram este manuscrito mais completo e consistente; à professora Margareth Kanarek pela revisão do texto; e a todo grupo de trabalho relacionado ao Projeto AERUM.

\section{Notas}

1 Salienta-se que as definições tipológicas presentes na tabela 1 não refletem uma interpretação funcional e/ou de Culturas Arqueológicas, a priori. A divisão baseiase unicamente nos aspectos morfológicos inerentes à cultura material, com o intuito de facilitar o diálogo com a comunidade arqueológica, cujas nomenclaturas apresentadas facilitam a compreensão.

\section{Referências}

ALVES, D. M. A Indústria Lítica do Sambaqui Mar Casado e outros sítios do litoral do Estado de São Paulo. 2010. 135 f. Dissertação (Mestrado em Arqueologia) - Programa de Pós-Graduação em
Arqueologia, Museu de Arqueologia e Etnologia, Universidade de São Paulo, São Paulo, 2010.

ANGUlO, R. J.; LESSA, G. C.; SOUZA, M. C. D. A critical review of mid - to late -Holocene sea level fluctuations on the eastern Brazilian coastline. Quaternary Science Reviews, v. 25, n. 5-6, p. 486-506, 2006.

BELÉM, F. R.; DEBLASIS, P. A indústria lítica do sambaqui do Morrote, Santa Catarina. Cadernos do LEPAARQ, v. 12, n. 23, Pelotas, p. 43-69, 2015.

BONOMO, M.; ANGRIZANI, R. C.; APOLINAIRE, E.; NOELLI, F. S. A model for the Guaraní expansion in the La Plata Basin and littoral zone of southern Brazil. Quaternary International, v. 356, p. 54-73, 2015.

BRONK RAMSEY, C.; SCOTT, M.; VAN DER PLICHT, H. Calibration for archaeological and environmental terrestrial samples in the time range 26-50 ka cal BP. Radiocarbon, v. 55, n. 4, p. 20212027, 2013.

BUENO, L.; DIAS, A. S. Povoamento inicial da América do Sul - contribuições do contexto brasileiro. Estudos Avançados, v. 29, n. 83, 2015.

BUENO, L.; DIAS, A. S.; STEELE, J. A Late Pleistocene/early Holocene archaeological 14C database for Central and South America: palaeoenvironmental contexts and demographic interpretations. Quaternary International, v. 301, p. 1-2, 2013.

CALDARELLI, S. B. Parecer técnico acerca do valor do patrimônio cultural e natural da região situada entre a barra de Laguna, município de Laguna, e a barra do Rio Araranguá, município de Araranguá, para fins de tombamento e de criação de uma unidade de conservação. Florianópolis: Scientia Ambiental, 2003.

CAMPOS, J. B. Salvamento Arqueológico na Jazida de Argila de Linha Rovaris, Turvo - Santa Catarina. Relatório Final. Criciúma: UNESC, 2008.

Salvamento Arqueológico na Jazida de Argila de Taquaruçú Ermo - Santa Catarina - 
Relatório Final, Santa Catarina, Brasil. Relatório Final. Criciúma: UNESC, 2009.

Programa de Salvamento Arqueológico na Jazida de Argila de Vila Maria, município de Nova Veneza/SC. Relatório Final. Criciúma: UNESC, 2010.

Programa de Resgate Arqueológico da Jazida de Argila Araçá, município de Nova Veneza - Santa Catarina. Relatório Final. Criciúma: UNESC, 2011.

Arqueologia Entre Rios e Gestão Integrada do Território no Extremo Sul de Santa CatarinaBrasil. 2015. 261 f. Tese (Doutorado em Arqueologia) - Universidade do Trás-os-Montes e Alto Douro, Vila Real, Portugal, 2015.

.; RIBEIRO, L. S.; RICKEN, C.; ROSA, R. C.; SAVI, C. N.; ZOCCHE, J. J. As gravuras rupestres do projeto encostas da serra no sul do estado de Santa Catarina, Brasil. Arkeos, Jornadas de Arqueologia Iberoamericana, n. 32, p. 121-132, 2012.

; SANTOS, M. C. P. Programa de Resgate Arqueológico da Jazida de Areia Eckert Campo Mãe Luzia, município de Araranguá, Santa Catarina, Brasil. Relatório Final. Criciúma: UNESC, 2014.

.; SANTOS, M. C. P.; ROSA, R. C.; RICKEN, C.; ZOCCHE, J. J. Arqueologia Entre Rios: do Urussanga ao Mampituba. Registros arqueológicos pré-históricos no extremo sul catarinense. Cadernos do LEPAARQ, Pelotas, v. 10, n. 20, p. 9-40, 2013.

CANCELLI, R. R. Evolução paleoambiental da Planície Costeira sul catarinense (Lagoa do Sombrio) durante o Holoceno, com base em dados palinológicos. 2012. 159 f. Tese (Doutorado em Geociências) - Programa de Pós-Graduação em Geociências, Universidade Federal do Rio Grande do Sul, Porto Alegre, 2012.

CEZARO, H. S.; BRAGA, A. S.; SANTOS, M. C. P.; ZOCCHE, J. J.; CAMPOS, J. B. A arte rupestre do Extremo Sul Catarinense: O caso do sítio Malacara I, Santa Catarina, Brasil. Revista de Tecnologia e Ambiente, v. 17, p. 133-149, 2011.
; FERREIRA, J. R.; SANTOS, M. C. P.; ZOCCHE, J. J.; CAMPOS, J. B. Gravuras Rupestres Registradas no Projeto de Pesquisa Arqueologia Entre Rios: do Urussanga ao Mampituba. Revista de Tecnologia e Ambiente, v. 19, p. 135-150, 2013.

COLONESE, A. C.; COLLINS, M.; LUCQUIN, A.; EUSTACE, M.; HANCOCK, Y.; POZONI, R. A. R.; MORA, A.; SMITH, C.; DEBLASIS, P.; FIGUTI, L.; WESOLOWSKI, V.; PLENS, C. R.; EGGERS, S.; SCUNDERLICK E. F. D.; GLEDHILL, A.; CRAIG, O. E. Long-term resilience of late Holocene coastal subsistence system in southeastern South America. PLOS One, v. 9, p. 1-13, 2014.

CORTEletTi, R. Projeto Arqueológico Alto Canoas - PARACA: um estudo da presença Jê no planalto catarinense. 2012. 342 f. Tese (Doutorado em Arqueologia) - Programa de Pós-Graduação em Arqueologia, Museu de Arqueologia e Etnologia, Universidade de São Paulo, São Paulo, 2012.

DEBLASIS, P.; KNEIP, A.; SCHEEL-YBERT, R.; GIANNINI, P. C.; GASPAR, M. D. Dinâmica natural e arqueologia regional no litoral do sul do Brasil. Arqueología suramericana/arqueologia sulamericana, v. 3, n. 1, p. 29-61, 2007.

DEBLASIS, P. A. D; GASPAR, M. D. Sambaquis do sul catarinense: retrospectiva e perspectivas de dez anos de pesquisas. Especiaria, v. 11/12, p. 20-30, 2009.

DIAS, A. S. Sistemas de assentamento e estilo tecnológico: uma proposta interpretativa para a ocupação pré-colonial do alto vale do rio dos Sinos, Rio Grande do Sul. 2003. Tese (Doutorado em Arqueologia) - Programa de Pós-Graduação em Arqueologia, Museu de Arqueologia e Etnologia da Universidade de São Paulo, São Paulo, 2003.

DIAS, A. S. Novas perguntas para um velho problema: escolhas tecnológicas como índices para o estudo de fronteiras e identidades sociais no registro arqueológico. Bol. Mus. Paraense Emílio Goeldi, Belém, v. 2, n. 1, p. 59-76, jan./abr. 2007.

Hunter-gatherer occupation of South Brazilian Atlantic Forest: paleoenvironment and 
archaeology. Quaternary International, v. 256, p. 12-18, 2012.

DUARTE, G. M. Depósitos cenozóicos costeiros e morfologia do extremo sul de Santa Catarina. 1995. 300 f. Tese (Doutorado em Geologia Sedimentar) Programa de Pós-Graduação em Geologia Sedimentar, Universidade de São Paulo, São Paulo, 1995.

EMPRESA DE PESQUISA AGROPECUÁRIA E DE EXTENSÃO RURAL DE SANTA CATARINA S.A. (EPAGRI); CENTRO INTEGRADO DE INFORMAÇÕES DE RECURSOS AMBIENTAIS DE SANTA CATARINA (CIRAM). Dadose Informações Biofísicas da Unidade de Planejamento Regional Litoral Sul Catarinense (UPR 8). Florianópolis: [s.n.], 2011.

FARIAS, D. S. E. Levantamento Arqueológico pré-colonial do município de Maracajá - SC. In: FARIAS, D. S. E. de. (Org.). Maracajá: pré-história e arqueologia. Tubarão: Editora Unisul, 2005. p. 61-78.

.; NEU, M. R.; DEMATHÉ, A.; GUIMARÃES, G. M.; ATORRE, T. AMA - Arqueologia na Mata Atlântica. Tempos Acadêmicos, v. 11, p. 185-209, 2013.

.; SCHMITZ, P. I. Linguagem, Dispersão e Diversidade das Populações Macro-Jê no Brasil Meridional durante a Pré-História Brasileira. Tubarão: Editora da UNISUL, 2012.

FOSSARI, T. Estudos Ambientais a Nível de Inventário para a Implantação da Rodovia Interpraias no Estado de Santa Catarina (São João do Sul - Laguna). Florianópolis: Ambiental Consultoria e Planejamento Ltda., 1991.

GIANNINI, P. C. F.; SAWAKUCHI, A. O.; MARTINHO, C. T.; TATUMI, S. H. Eolian depositional episodes controlled by Late Quaternary relative sea level changes on the Imbituba, Laguna coastal zone (southern Brazil). Marine Geology, v. 237, p. 143-168, 2007.

.; VILLAGRAN, X. S.; FORNARI, M.; RODRIGUES, D.; MENEZES, P.; TANAKA, A.
P.; ASSUNÇÃO, D.; DE BLASIS, P.; AMARAL, P. Interações entre Evolução Sedimentar e Ocupação Humana Pré-histórica na Costa Centro-sul de Santa Catarina, Brasil. Boletim do Museu Paraense Emílio Goeldi, v. 5, n. 1, p. 105-28, 2010.

GLUCHY, M. É. F.; SALLES, J. M. Análise tecnofuncional do material polido do extremo sul do Rio Grande do Sul, Brasil. In: .; LOURDEAU, A. (Org.). Povoamento e modalidades de ocupação humana na América do Sul: a contribuição da tecnologia lítica. Prigonrieux: Archéo-éditions.com, 2014. p. 12-35.

HORN FILHO, N. O. Setorização da Província Costeira de Santa Catarina em base aos aspectos geológicos, geomorfológicos e geográficos. Geosul, v. 18, n. 35, p. 71-94, 2003.

INSTITUTO BRASILEIRO DE GEOGRAFIA E ESTATÍSTICA (IBGE). Manual técnico da vegetação brasileira. Rio de Janeiro: [s.n.], 1992.

JUSTUS, J. O.; MACHADO, M. L. A.; FRANCO, M. S. M. Geomorfologia. In: Projeto RADAMBRASIL. Folha SH-22 - Porto Alegre e parte das folhas SH21 - Uruguaiana e SI-22 - Lagoa Mirim, Rio de Janeiro, 1986. p. 313-404 (Levantamento de Recursos Naturais, v. 33).

KAUL, P. F. T. Geologia. In: INSTITUTO BRASILEIRO DE GEOGRAFIA E ESTATÍSTICA. Geografia do Brasil: Região Sul. Rio de Janeiro: IBGE, 1990. p. 29-54.

KREBS, A. S. J. Contribuição ao conhecimento dos recursos hídricos subterrâneos da bacia hidrográfica do rio Araranguá, SC. 2004. 375 f. Tese (Doutorado em Geografia) - Programa de PósGraduação em Geografia, Universidade Federal de Santa Catarina, Florianópolis, 2004.

LAMING-EMPERAIRE, A. Guia para o estudo das indústrias líticas da América do Sul. In: Universidade Federal do Paraná. Manuais de arqueologia. Curitiba: UFPR, 1967. 
LAVINA, R. Projeto de Levantamento Arqueológico Rodovia Interpraias: Içara-Araranguá/SC. $1^{\circ} \mathrm{e}$ $2^{\circ}$ Relatórios Parciais. Criciúma: IPAT/UNESC, 1997-1998.

Projeto de Salvamento Arqueológico da Rodovia Interpraias (trecho Morro dos Conventos a Lagoa dos Esteves, Araranguá-Içara, SC). Relatório Final. Criciúma: UNESC, 2000.

Sítios Arqueológicos Litorâneos. In: CALDARELLI, S. B. Parecer técnico acerca do valor do patrimônio cultural e natural da região situada entre a barra de Laguna, município de Laguna, e a barra do Rio Araranguá, município de Araranguá, para fins de tombamento e de criação de uma unidade conservação. Florianópolis: [s.n.], 2003. p. 107-142.

Levantamento Arqueológico da Jazida Eckert. Relatório Final. Criciúma: UNESC, 2005.

LEITE, P. F.; KLEIN, R. M. Vegetação. In: IBGE. Fundação Instituto Brasileiro de Geografia e Estatística. Geografia do Brasil: Região Sul. Rio de Janeiro: IBGE, 1990. p. 113-150.

LINO, J. T. Arqueologia Guarani no vale do rio Araranguá: aspectos de territorialidade e variabilidade funcional. Erechim: Habilis, 2009.

.; CAMPOS, J. B. Expedições arqueológicas do sul do estado de Santa Catarina. Revista de Ciências Humanas, v. 9, n. 1, Criciúma, p. 17-34, 2003.

MAACK, R. Breves notícias sobre a geologia dos estados de Santa Catarina e Paraná. Arquivos de Biologia e Tecnologia, v. 2, Rio de Janeiro, p. 65-154, 1947.

MILHEIRA, R. G. Arqueologia Guarani no litoral sul-catarinense: história e território. 2010. 224 f. Tese (Doutorado em Arqueologia) - Programa de Pós-Graduação em Arqueologia, Museu de Arqueologia e Etnologia, Universidade de São Paulo, São Paulo, 2010.
Os Guarani e seus artefatos: um estudo tecnológico no sul do Brasil. Revista do Museu de Arqueologia e Etnologia, n. 21, São Paulo, p. 129152, 2011.

; DEBLASIS, P. Ocupação do território Guarani no litoral sul-catarinense. Cuadernos del Instituto Nacional de Antropología y Pensamiento Latinoamericano, v. 1, n. 4, Buenos Aires, p. 148-160, 2013.

MORAIS J. L. de. A Arqueologia e o Fator Geo. Revista do Museu de Arqueologia e Etnologia, São Paulo, v. 9, p. 3-22, 1999.

NOELLI, F. S. Sem tekohá não há tekó: em busca de um modelo etnoarqueológico da aldeia e da subsistência Guarani e sua aplicação a uma área de domínio no delta do Jacuí-RS. 1993. 488 f. Dissertação (Mestrado em História) - Programa de Pós-Graduação em História, Pontifícia Universidade Católica do Rio Grande do Sul, Porto Alegre, 1993.

A ocupação humana na região sul do Brasil: arqueologia, debates e perspectivas - 1872/2000. Revista USP, n. 44, São Paulo, p. 218-269, 1999-2000.

OKUMURA, M. M. M.; ARAUJO, A. G. M. Pontas bifaciais no Brasil Meridional: caracterização estatística das formas e suas implicações culturais. Revista do Museu de Arqueologia e Etnologia, v. 13, São Paulo, p. 111-127, 2013.

.;____ Long-term cultural stability in hunter e gatheres: a case study using traditional and geometric morphometric analysis of lithic stemmed bifacial points from Southern Brazil. Journal of Archaeological Science, n. 45, p. 59-71, 2014.

PAUWELLS, G. A morfogênese do litoral catarinense. Revista Brasileira de Geografia, Rio de Janeiro, v. 3, n. 4, p. 785-804, 1941.

PAVEI, D.; CAMPOS, J.; SANTOS, M. Entre a Caça a Pesca e a Coleta: a fauna na dieta pré-histórica no Litoral do Extremo Sul Catarinense: entre 1300- 
500 anos BP. [Comunicação Oral]. III Encuentro Latinoamericano de Zooarqueología. Laboratório de Bioarqueologia do Departamento de Arqueologia da Universidade Federal de Sergipe, Brasil, 2016.

PEREIRA, G. S.; NOELLI, F. S.; CAMPOS, J. B.; ZOCCHE, J. J.; SANTOS, M. C. P. Ecologia Histórica Guarani: As plantas utilizadas no Bioma Mata Atlântica do litoral sul de Santa Catarina, Brasil (Parte 1). Cadernos do LEPAARQ, v. XIII, n. 26, p. 197-246, 2016.

RICKEN, C.; ROSA. R. C.; MENEGHINI, J. W.; CAMPOS, J. B.; ZOCCHE, J. J. A dinâmica da paisagem e o povoamento pré-histórico no sul de Santa Catarina. Tempos Acadêmicos, v. 11, Criciúma, p. 163-184, 2013.

ROGGE, J. H.; ARNT, F. V. O Sambaqui de Içara SC-IÇ-06. Pesquisas, Antropologia, São Leopoldo, n. 63, p. 13-16, 2006.

ROHR, J. A. Pesquisas Arqueológicas no Município Catarinense de Urussanga. Anais do Museu de Antropologia da UFSC. Florianópolis: UFSC, ano XI-XIV, n. 12, 13, 14, 15, 1982. p. 48-59.

ROSA, A. O. Arqueofauna de um sítio litorâneo do Estado de Santa Catarina. Revista de Arqueologia, n. 11, São Paulo, p. 3-6, 1998.

Remanescentes da fauna e flora. Pesquisas, Antropologia, São Leopoldo, n. 55, p. 31-64, 1999.

Composição e diversidade da arqueofauna dos sítios de Içara: SC-IÇ-01 e SC-IC-06. Pesquisas, Antropologia, São Leopoldo, v. 63, p. 33-54, 2006.

SANTA CATARINA. Gabinete de Planejamento e Coordenação Geral. Subchefia de Estatística, Geografia e Informática. Atlas de Santa Catarina. Rio de Janeiro: Aerofoto Cruzeiro, 1986.

SANTA CATARINA. Secretaria de Estado do Desenvolvimento Urbano e Meio Ambiente. Bacias hidrográficas do estado de Santa Catarina: Diagnóstico Geral. Florianópolis: SEDUMA, 1997.
SANTOS, J.; SANTOS, M. C. P.; CAMPOS, J. B. História Indígena: O Percalço das Fontes Documentais. História e-História, Campinas, v. 1, p. 1-9, 2014.

SANTOS, M. C. P.; COSTA, J. G.; CAMPOS, J. B. Escolhas de Matérias-Primas Rochosas por Grupos Pré-Históricos Caçadores-Coletores na Microbacia do Rio da Pedra, Jacinto Machado/Santa Catarina. Cadernos do LEPAARQ (UFPEL), v. 12, Pelotas, p. 23-42, 2015.

SCHEIBE, L. F. Como se formou a bacia do rio Araranguá? In: SCHEIBE, L. F.; BUSS, M. D.; FURTADO, S. M. A. (Org.). Atlas ambiental da bacia do rio Araranguá. Florianópolis: Cidade Futura, 2010. v. 1. p. 13-15.

SCHMITZ, P. I. Acampamentos Litorâneos em IçaraSC: Um Exercício em Padrão de Assentamento. Clio 1, v. 11, p. 99-118, 1995-1996.

Continuidade e Mudança no Litoral de Santa Catarina. Revista do Museu de Arqueologia e Etnologia, São Paulo, v. 8, 1998.

A ocupação pré-histórica do Estado de Santa Catarina. Tempos Acadêmicos, v. 11, p. 6-24, 2013. .; ROSA, A. O.; IZIDRO, J. M.; HAUBERT, F.; KREVER, M. L. B.; BITENCOURT, A. L. V.; ROGGE, J. H.; BEBER, M. V. Içara: Um Jazigo Mortuário no Litoral de Santa Catarina. Pesquisas, Antropologia, São Leopoldo, n. 55, p. 1-164, 1999.

.; ARNT, F. V.; BEBER, M. V.; ROSA, A. O.; ROGGE, J. H. Taió, no Vale do Rio Itajaí, SC. O encontro de antigos caçadores com as casas subterrâneas. Pesquisas, Antropologia, São Leopoldo, n. 67, p. 185-320, 2009.

SOARES, A. L. R. Guarani: organização social e arqueologia. Porto Alegre: EDIPUCRS, 1997.

SUGUIO, K.; MARTIN, L.; BITTENCOURT, A. C. S. P.; DOMINGUES, J. M. L.; FLEXOR, J. M.; AZEVEDO, A. E. G. Flutuações do nível relativo do mar durante o Quaternário Superior ao longo do 
litoral brasileiro e suas implicações na sedimentação costeira. Revista Brasileira de Geociências, v. 15, n. 4, p. 273-286, 1985.

TAMIOZZO, V.; ROSA, A. O.; SCHMITZ, P. I. Investigações Zooarqueológicas no Sambaqui SCIÇ-06 Içara-SC. Canindé, v. 12, p. 105, 2008.

TEIXEIRA, D. R. Arqueofauna do sítio SC-IÇ-06. Pesquisas, Antropologia, São Leopoldo, n. 63, p. 17-32, 2006.

TEIXEIRA, M. B.; NETO, A. B. C.; PASTORE, U.; RANGEL FILHO, A. L. R. Vegetação. In: FUNDAÇÃO INSTITUTO BRASILEIRO DE GEOGRAFIA E ESTATÍSTICA. Folha SH. 22 Porto Alegre e parte das folhas SH. 21 Uruguaiana e SI. 22
Lagoa Mirim: geologia, geomorfologia, pedologia, vegetação, uso potencial da terra. Rio de Janeiro: IBGE, 1986. p. 541-632. (Levantamento de Recursos Naturais, v. 33).

VAL, C. Ocupação pré-histórica e mudanças paleoambientais na planície costeira sulcatarinense: abordagem integrada com base em dados palinológicos. 2015. 147 f. Dissertação (Mestrado em Quaternário e pré-história) - Master Erasmus Mundus em Quaternário e Pré-História, Portugal, 2015.

VILLWOCK, J. A.; TOMAZELLI, L. J. Holocene coastal evolution in Rio Grande do Sul, Brazil. Quaternary of South America and Antarctic Peninsula, v. 11, p. 283-296, 1998. 